\title{
WestVirginiaUniversity
}

THE RESEARCH REPOSITORY @ WVU

Graduate Theses, Dissertations, and Problem Reports

2009

\section{A kinetic study of decyl phosphite stabilizers}

John K. Snodgrass

West Virginia University

Follow this and additional works at: https://researchrepository.wvu.edu/etd

\section{Recommended Citation}

Snodgrass, John K., "A kinetic study of decyl phosphite stabilizers" (2009). Graduate Theses,

Dissertations, and Problem Reports. 2164.

https://researchrepository.wvu.edu/etd/2164

This Thesis is protected by copyright and/or related rights. It has been brought to you by the The Research Repository @ WVU with permission from the rights-holder(s). You are free to use this Thesis in any way that is permitted by the copyright and related rights legislation that applies to your use. For other uses you must obtain permission from the rights-holder(s) directly, unless additional rights are indicated by a Creative Commons license in the record and/ or on the work itself. This Thesis has been accepted for inclusion in WVU Graduate Theses, Dissertations, and Problem Reports collection by an authorized administrator of The Research Repository @ WVU. For more information, please contact researchrepository@mail.wvu.edu. 
A KINETIC STUDY OF DECYL PHOSPHITE STABILIZERS

John K. Snodgrass

Thesis submitted to the College of Engineering and Mineral Resources at West Virginia University in partial fulfillment of the requirements for the degree of

Master of Science

in

Chemical Engineering

Joseph A. Shaeiwitz, Ph.D., Chair Edwin L. Kugler, Ph.D.

Richard Turton, Ph.D.

Department of Chemical Engineering

Morgantown, West Virginia

2009

Keywords: Kinetic; Phosphite; Michaelis-Menten

Copyright 2009 John K. Snodgrass 


\section{A B S T R A C T}

\section{A Kinetic Study of Decyl Phosphite Stabilizers}

\section{John K. Snodgrass}

Decyl phosphite stabilizers are used to improve the molecular stability of polymers during processing and end use giving durability to the many plastic products used in daily life. By understanding the governing kinetics of the decyl phosphite reaction system, improvements and alternative manufacturing methods may be possible. Diphenyl isodecyl phosphite, phenyl diisodecyl phosphite, and tri-isodecyl phosphite are the products of reacting isodecanol and triphenyl phosphite in the presence a sodium methylate. Concentration and time data were collected by performing laboratory reactions at various reactant ratios and temperatures.

Analysis of laboratory data shows that the system can be adequately described by five coupled ordinary differential equations resulting from power-law kinetic theory at the lower temperature range studied. The frequency factors associated with the rate constants vary with initial reactant ratio. As the phosphite reaction rates increase the power-law kinetic model losses accuracy. This is believed to be due to limiting interactions with the sodium decylate intermediate. A kinetic model following a Michaelis-Menten form with two reactants has the potential to adequately describe the system under these conditions. 


\section{TABLE OF CONTENTS}

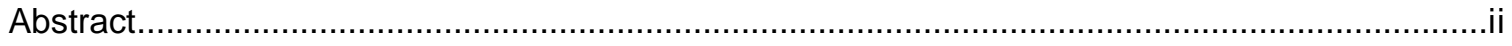

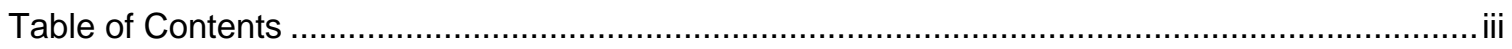

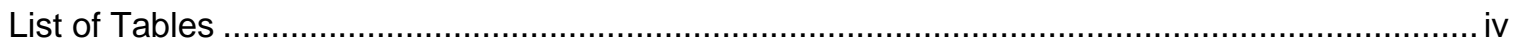

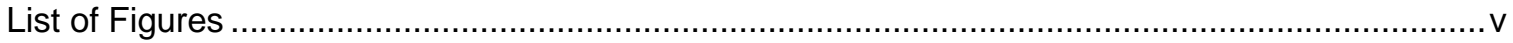

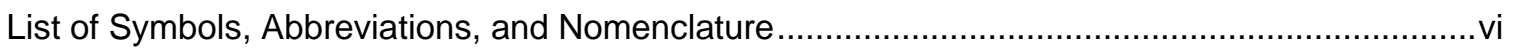

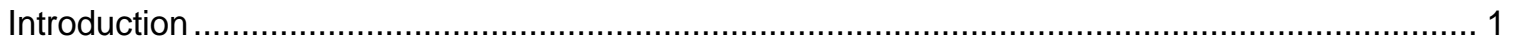

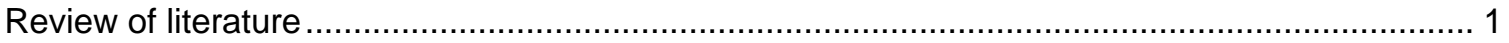

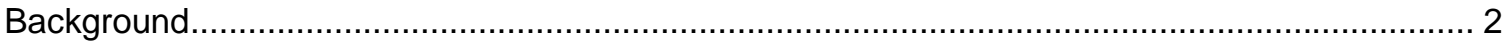

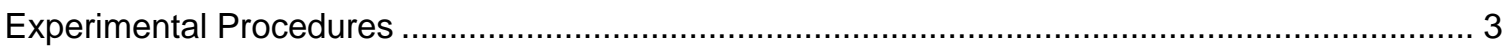

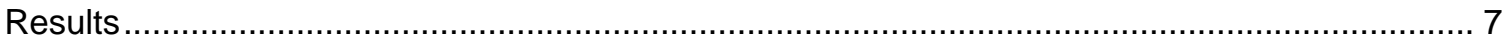

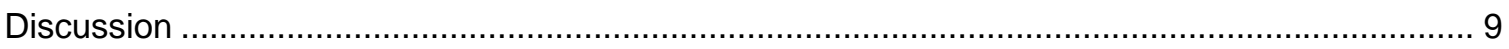

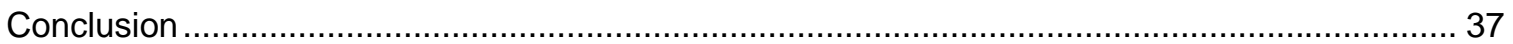

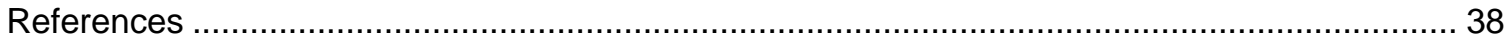




\section{LIST OF TABLES}

Table 1: Typical laboratory reaction charge amounts 3

Table 2: Arrhenius equation constants $\quad 7$

Table 3: Regressed reaction coefficients for Equations 23 through $27 \quad 22$

Table 4: Coefficients for polynomial fit of Arrhenius equation parameters to reactant ratio 28

Table 5: Rate constants for Equations 31 and 35

Table 6: Regression results for Equations 38 through 42 for reactant ratio of $2.5: 1$ at $110^{\circ} \mathrm{C} \quad 34$ 


\section{LIST OF FIGURES}

Figure 1: Laboratory reactor apparatus 4

Figure 2: Typical GPC results $\quad 5$

$\begin{array}{ll}\text { Figure 3: Typical GC results } & 6\end{array}$

Figure 4: Results from 1:1 isodecanol to TPP ratio at $110^{\circ} \mathrm{C} \quad 10$

Figure 5: Results from 2.5:1 isodecanol to TPP ratio at $110^{\circ} \mathrm{C} \quad 11$

Figure 6: Results from 5:1 isodecanol to TPP ratio at $110^{\circ} \mathrm{C} \quad 12$

Figure 7: Results from 1:1 isodecanol to TPP ratio at $130^{\circ} \mathrm{C}$

Figure 8: Results from 2.5:1 isodecanol to TPP ratio at $130^{\circ} \mathrm{C} \quad 14$

Figure 9: Results from 5:1 isodecanol to TPP ratio at $130^{\circ} \mathrm{C} \quad 15$

Figure 10: Results from 1:1 isodecanol to TPP ratio at $150^{\circ} \mathrm{C} \quad 16$

Figure 11: Results from 2.5:1 isodecanol to TPP ratio at $150^{\circ} \mathrm{C} \quad 17$

Figure 12: Results from 5:1 isodecanol to TPP ratio at $150^{\circ} \mathrm{C} \quad 18$

Figure 13: Results from 2.5:1 isodecanol to TPP ratio at $130^{\circ} \mathrm{C}$ with 0.04 grams of sodium

$\begin{array}{ll}\text { methylate } & 19\end{array}$

Figure 14: Results from 2.5:1 isodecanol to TPP ratio at $130^{\circ} \mathrm{C}$ with 0.4 grams of sodium

$\begin{array}{ll}\text { methylate } & 20\end{array}$

Figure 15: Power law kinetic model comparison for $2.5: 1$ reactant ratio at $110^{\circ} \mathrm{C}$

Figure 16: Power law kinetic model comparison for 2.5:1 reactant ratio at $130^{\circ} \mathrm{C}$

Figure 17: Power law kinetic model comparison for 2.5:1 reactant ratio at $150^{\circ} \mathrm{C} \quad 25$

Figure 18: General power law kinetic model comparison for $2.5: 1$ reactant ratio at $110^{\circ} \mathrm{C} \quad 27$

Figure 19: Michaelis-Menten coefficient determination at $110^{\circ} \mathrm{C} \quad 31$

Figure 20: Michaelis-Menten coefficient determination at $130^{\circ} \mathrm{C} \quad 32$

Figure 21: Michaelis-Menten coefficient determination at $150^{\circ} \mathrm{C} \quad 33$

Figure 22: Two-reactant Michaelis-Menten kinetic model comparison for 2.5:1 reactant ratio at $110^{\circ} \mathrm{C}$ 


\section{LIST OF SYMBOLS, ABBREVIATIONS, AND}

\section{NOMENCLATURE}

$\phi \quad$ - Phenyl group, $\mathrm{C}_{6} \mathrm{H}_{5}$

$R \quad$ - Alkyl group, straight or branched chain

$k_{x} \quad$ - Reaction rate constant for component $\mathrm{X}$ or equation $\mathrm{X}$

$K_{x} \quad$ - General Michaelis constant for equation X

TPP - Triphenyl phosphite, $(\phi O)_{3} P$

DPDP - Diphenyl isodecyl phosphite, $(\phi O)_{2} P O R$

PDDP - Phenyl di-isodecyl phosphite, $\phi O P(O R)_{2}$

TDP - Tri-isodecyl phosphite, $P(O R)_{3}$ 


\section{INTRODUCTION}

Polymer stabilizers provide essential protection against molecular degradation caused by trace free radicals by providing active sites for free radical attack. This degradation results in lower polymer molecular weight, lower viscosities, and discoloration. Phosphite chemistry has been used over the last fifty years to provide stabilization of various polymers during such processing as heating, bending, and extrusion.

Commercial phosphite stabilizer production commonly begins with the production of triphenyl phosphite by reacting phosphorous trichloride with phenol. The triphenyl phosphite is then reacted with an alcohol in the presence of sodium methylate. The resulting transesterification reaction yields an alkyl phosphite mixture, phenol, and sodium salt particulate.

One specific set of phosphite stabilizers is produced using isodecanol as the reacting alcohol by batch reaction and product stripping. The mixture of stabilizers contains diphenyl isodecyl phosphite, phenyl di-isodecyl phosphite, and tri-isodecyl phosphite. These products are commonly called DPDP, PDDP, and TDP, respectively. The stabilizers differ in stabilization characteristics and are therefore available commercially in three grades corresponding to the dominant stabilizer in the product mixture.

The purpose of this research is to gain insight to the isodecanol-triphenyl phosphite reaction system so that improvements in manufacturing can be made. These improvements may range from optimizing current operating conditions to new manufacturing methods. A kinetic model of the reaction system can provide this insight.

\section{REVIEW OF LITERATURE}

No United States patents have been found involving the study of this system. No published items regarding the kinetics of this reaction system have been found. 


\section{BACKGROUND}

Detailed information regarding the mechanisms and kinetics of the triphenyl phosphite / isodecanol reaction system has not been fully investigated and documented. Sodium methylate is added to the reactant mix in a small amount and is commonly referred to as the 'catalyst'.

Conversations with experienced employees led to insight about this system.

During discussions with an engineer ${ }^{1}$, the reaction system was described according to Equations 1 through 3.

$$
\begin{aligned}
& (\phi O)_{3} \mathrm{P}+\mathrm{ROH} \stackrel{K_{1}}{\longleftrightarrow}(\phi \mathrm{O})_{2} \mathrm{POR}+\phi \mathrm{OH} \\
& (\phi O)_{2} \mathrm{POR}+\mathrm{ROH} \stackrel{K_{21}}{\longleftrightarrow} \phi \mathrm{OP}(\mathrm{OR})_{2}+\phi \mathrm{OH} \\
& \phi \mathrm{OP}(\mathrm{OR})_{2}+\mathrm{ROH} \stackrel{K_{3}}{\longleftrightarrow} \mathrm{P}(\mathrm{OR})_{3}+\phi \mathrm{OH}
\end{aligned}
$$

This description has been based on observed plant-scale batch production. Commercial production allows one hour for reaction before proceeding to the purification step to remove the phenol by-product. Operational experience has shown that after the reaction step of the batch process, the phosphite reactions have not reached equilibrium. Operational data have suggested that the second and third substitutions occur during the phenol-stripping step. A logical deduction would be that the removal of phenol from the mixture allows the equilibrium to shift toward the desired product proportions. Constant-volume lab reactions were carried out that showed this not to be the case.

Several conversations with a process chemist ${ }^{2}$ have led to the current understanding of this reaction system. It was noted that the chemistry appeared to exhibit equilibrium-limited behavior based on laboratory observations. Further conversations led to the suggestion that the sodium methylate additive behaves as described in Equations 4 through 7.

$$
\begin{array}{r}
\mathrm{NaOCH}_{3}+\mathrm{ROH} \stackrel{K_{4}}{\longleftrightarrow} \mathrm{CH}_{3} \mathrm{OH}+\mathrm{NaOR} \\
(\phi O)_{X} \mathrm{P}(\mathrm{OR})_{Y}+\mathrm{NaOR} \stackrel{K_{5}}{\longleftrightarrow}(\phi \mathrm{O})_{(X-1)} \mathrm{P}(\mathrm{OR})_{(\mathrm{Y}+1)}+\mathrm{NaO} \phi \\
\mathrm{NaO} \phi+\mathrm{ROH} \stackrel{K_{6}}{\longleftrightarrow} \mathrm{NaOR}+\phi \mathrm{OH} \\
(\mathrm{OR})_{2} \mathrm{POH}+\mathrm{NaOR} \stackrel{K_{7}}{\longrightarrow}(\mathrm{RO})_{2} \mathrm{PONa}+\mathrm{ROH}
\end{array}
$$




\section{EXPERIMENTAL PROCEDURES}

The laboratory experiments are conducted by measuring out the reactants by weight using a typical analytical scale. Typical charge amounts are shown in Table 1. The reactants are placed in a 500-milliliter round-bottomed flask equipped with a mixer, automatic temperature

Table 1: Typical laboratory reaction charge amounts

\begin{tabular}{||c|c|c|c|c||}
\hline \hline Temperature, ${ }^{\circ} \mathbf{C}$ & Ratio & Isodecanol, g & TPP, g & Catalyst, g \\
\hline 110 & $1: 1$ & 101.06 & 199.05 & 0.0403 \\
\hline 110 & $2.5: 1$ & 168.1 & 132.15 & 0.0435 \\
\hline 110 & $5: 1$ & 215 & 87.3 & 0.0407 \\
\hline
\end{tabular}

control, and a nitrogen blanket. The desired reaction temperature is set and a sample is taken every fifteen minutes. The sample is drawn using a syringe through a rubber septum. Reaction is effectively halted by immediately diluting two drops of the sample with 10 milliliters of cyclohexane solvent. Sampling is continued until the analysis shows no significant changes between sequential samples. Figure 1 shows the apparatus.

Each sample is prepared by filtering about 1 milliliter of sample / solvent mixture into a chromatography vial. The vial is then placed into a chromatograph equipped with a gel permeation chromatography (GPC) packed column using tetrahydrofuran as the mobile phase. When properly calibrated, the GPC will show distinct peaks for DPDP, PDDP, TDP, and phenol. A draw back to the GPC analysis is the single peak that represents TPP also contains the isodecanol signal. Another chromatography vial is prepared and placed in a gas chromatograph equipped with a Varian CP7542 column. When properly calibrated, this will result in a strong TPP peak. The isodecanol amount is calculated by balance. Typical chromatography results are shown in Figures 2 and 3. Gauge repeatability and reproducibility studies have shown that the results from this equipment exhibit approximately $\pm 0.275 \%$ variability. When shown graphically, the error range is effectively smaller than the data markers representing the experimental results. 


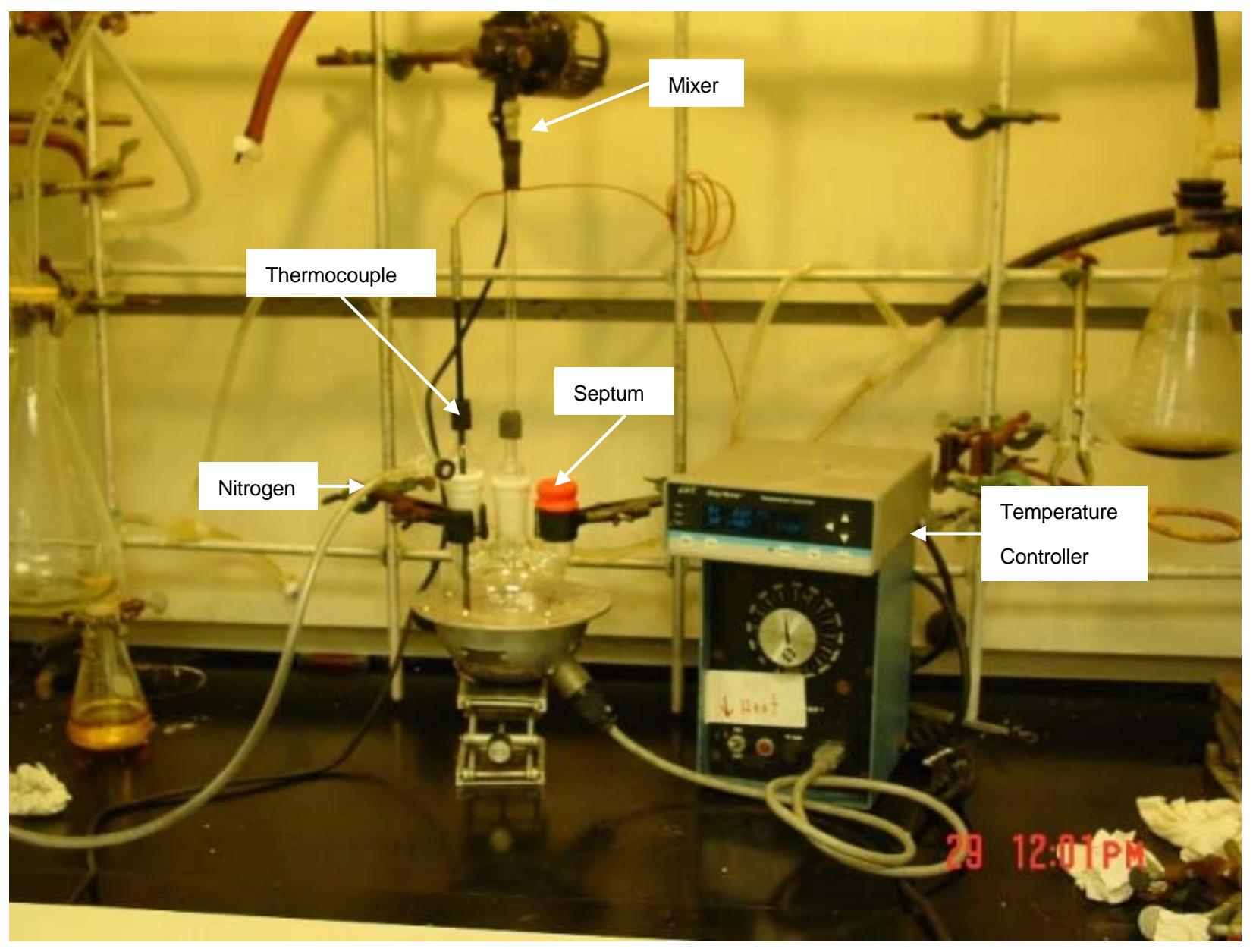

Figure 1: Laboratory reactor apparatus 
Data File C: \HPCHEM $\backslash 2 \backslash$ DATA \ESTERS $\backslash 373509 . D$

1.5G/ 1OML THF, FILTERED, T-1
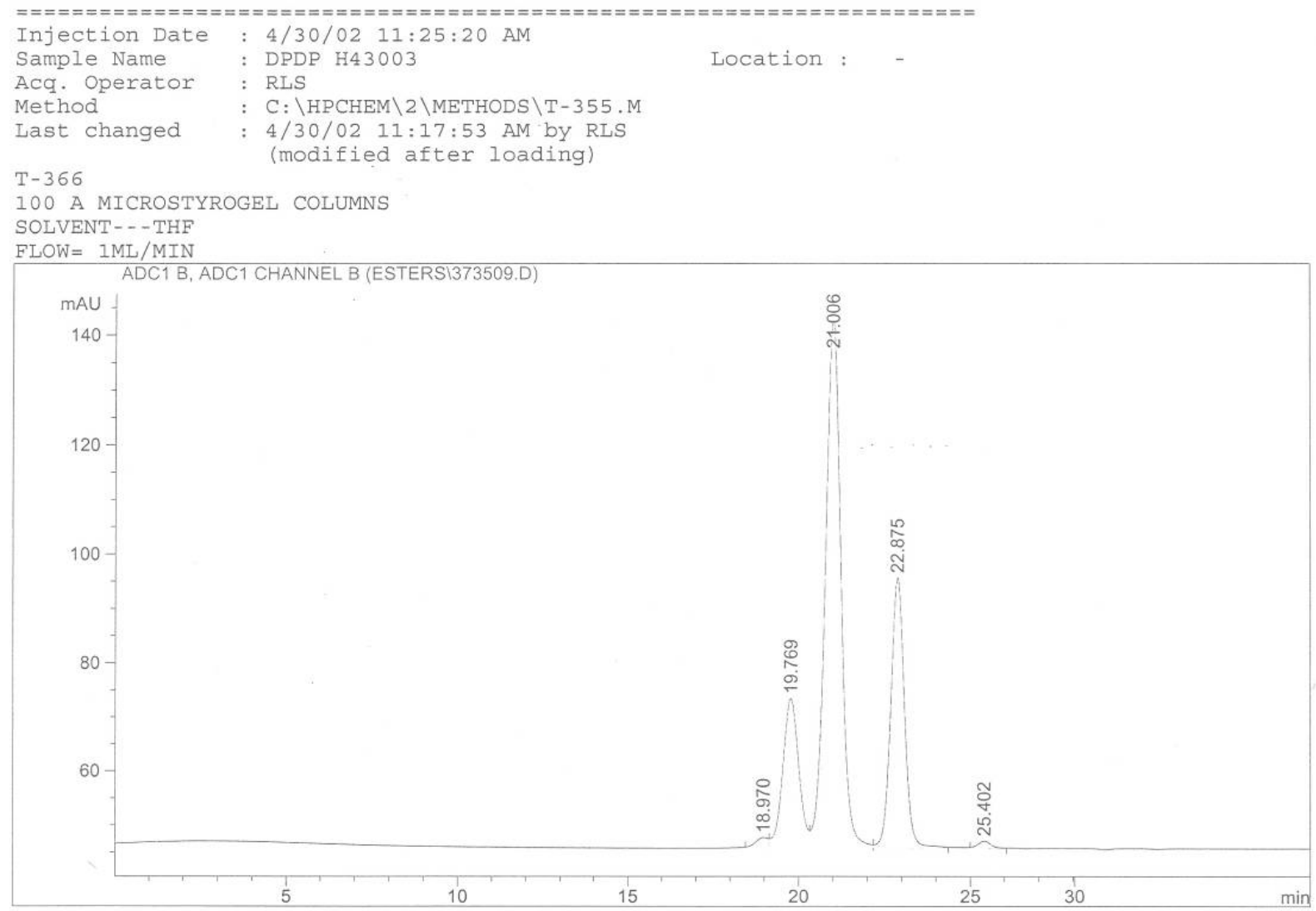

Area Percent Report

\begin{tabular}{|c|c|}
\hline Sorted By & Signal \\
\hline Multiplier & 1.0000 \\
\hline Dilution & 1.0000 \\
\hline
\end{tabular}

Signal 1: ADC1 B, ADC1 CHANNEL B

\begin{tabular}{|c|c|c|c|c|c|c|c|c|}
\hline $\begin{array}{c}\text { Peak } \\
\#\end{array}$ & $\begin{array}{c}\text { RetTime } \\
\text { [min] }\end{array}$ & Type & $\begin{array}{l}\text { Width } \\
\text { [min] }\end{array}$ & $\begin{array}{c}\text { Area } \\
{\left[\mathrm{mAU}{ }^{*} \mathrm{~s}\right]}\end{array}$ & $\begin{array}{l}\text { Height } \\
\text { [mAU] }\end{array}$ & $\begin{array}{c}\text { Area } \\
\frac{\circ}{6}\end{array}$ & & \\
\hline 1 & 18.970 & VV B & 0.3967 & 50.13572 & 1.94508 & 0.9171 & 1.8 ToP & \\
\hline 2 & 19.769 & VV & 0.4978 & 893.20203 & 27.58510 & 16.3393 & 24.2 PODP & \\
\hline 3 & 21.006 & VV & 0.4930 & 3097.44482 & 96.88845 & 56.6614 & 53.6 DEDP & \\
\hline 4 & 22.875 & VB & 0.4254 & 1389.41077 & 49.81670 & 25.4164 & $15.0 \mathrm{TPP}$ & 0.0 DELX \\
\hline 5 & 25.402 & $\mathrm{BB}$ & 0.3995 & 36.39412 & 1.32901 & 0.6658 & 0.4 & \\
\hline Total & Ls : & & & 5466.58746 & 177.56433 & & & \\
\hline
\end{tabular}

Figure 2: Typical GPC results 


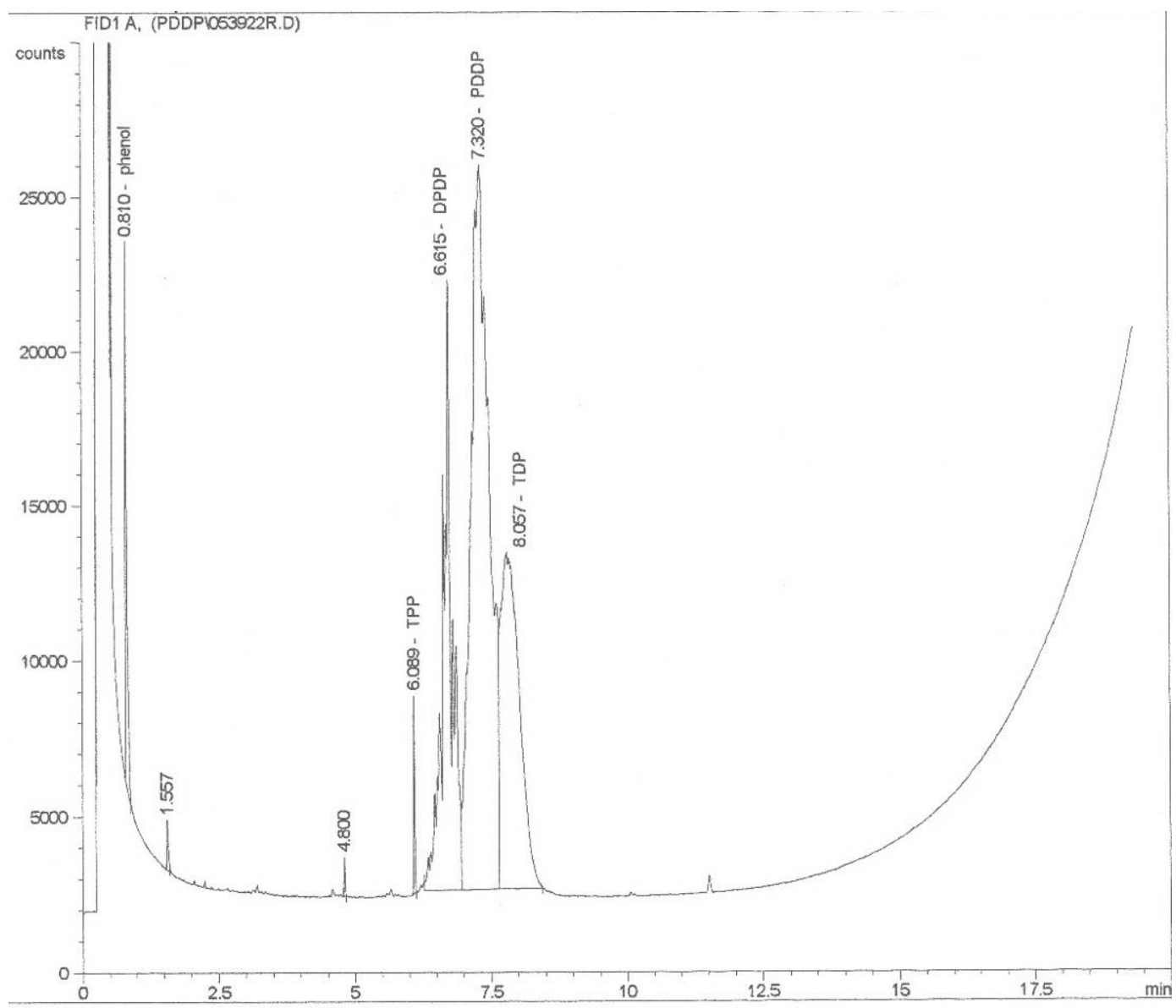

Data File C: \HPCHEM $1 \backslash$ DATA \PDDP $\backslash 053922 R$. D

Sample Name: T-8 HAZY

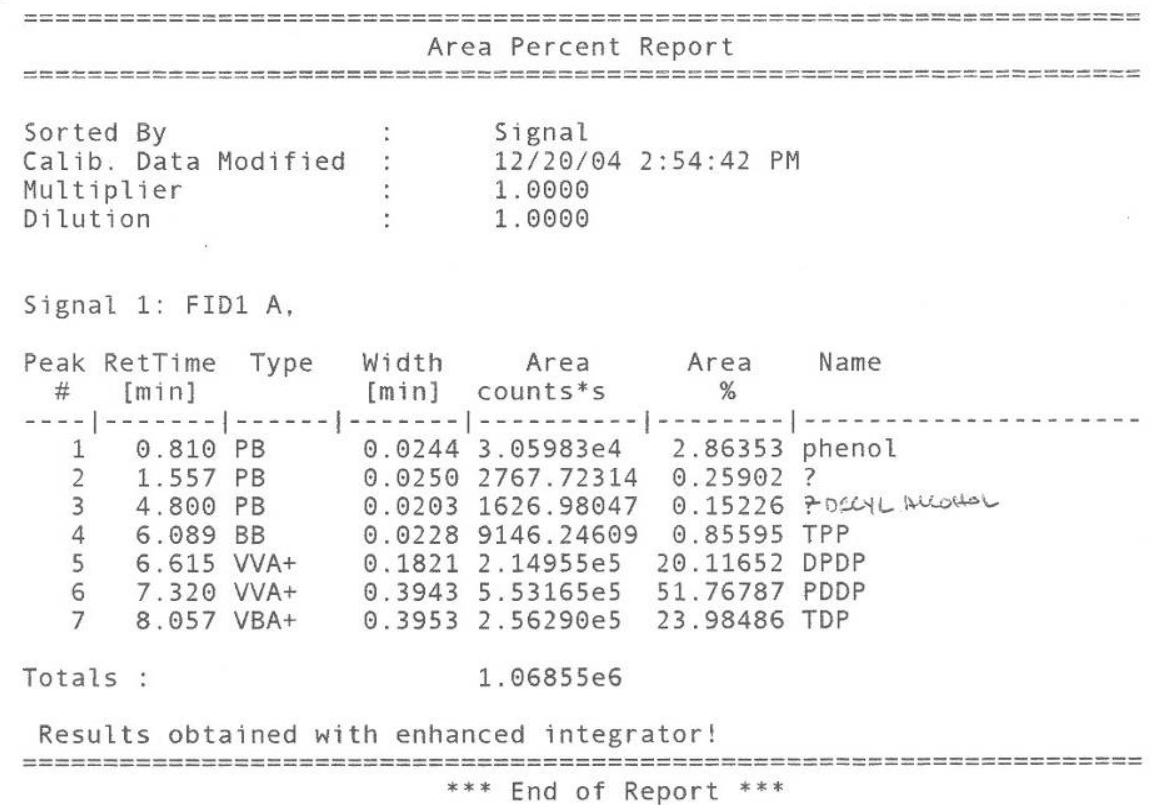

Figure 3: Typical GC results 


\section{RESULTS}

The decyl phosphite reaction system is given by Equations 8 through 12 . The rate relationships for the system are given in Equations 13 through 17. The reaction in Equation 8 is an initiation reaction and only provides for the start of the system. The reaction in Equation 12 is much faster relative to the other reactions. Based on this, the rate equations given in Equations 18 through 22 are representative of the rates of reaction. Table 2 contains the Arrhenius equation parameters found in the rate equations by initial reactant ratio. The rate equations are valid for temperatures between $110^{\circ} \mathrm{C}$ and $150^{\circ} \mathrm{C}$. There is a loss of accuracy as the temperature increases.

Table 2: Arrhenius equation constants

\begin{tabular}{|c|c|c|c|c|c|c|c|c|c||}
\hline & \multicolumn{3}{|c|}{$\boldsymbol{k}_{\text {TPP }}$} & \multicolumn{3}{c|}{$\boldsymbol{k}_{\text {DPDP }}$} & \multicolumn{3}{c|}{$\boldsymbol{k}_{\text {PDDP }}$} \\
\cline { 2 - 10 } & $\mathbf{1 : 1}$ & $\mathbf{2 . 5 : 1}$ & $\mathbf{5 : 1}$ & $\mathbf{1 : 1}$ & $\mathbf{2 . 5 : 1}$ & $\mathbf{5 : 1}$ & $\mathbf{1 : 1}$ & $\mathbf{2 . 5 : 1}$ & $\mathbf{5 : 1}$ \\
\hline$E(\mathrm{~J} / \mathrm{mol} \mathrm{K})$ & $1.78 \times 10^{4}$ & $9.99 \times 10^{3}$ & $9.77 \times 10^{2}$ & $1.85 \times 10^{5}$ & $7.92 \times 10^{4}$ & $5.51 \times 10^{4}$ & $5.03 \times 10^{4}$ & $1.42 \times 10^{4}$ & $4.07 \times 10^{4}$ \\
\hline$A\left(\mathrm{sec}^{-1}\right)$ & $7.63 \times 10^{-2}$ & $8.23 \times 10^{-3}$ & $5.26 \times 10^{-4}$ & $2.56 \times 10^{20}$ & $3.30 \times 10^{6}$ & $3.25 \times 10^{3}$ & $2.90 \times 10^{2}$ & $7.51 \times 10^{-3}$ & $1.02 \times 10^{1}$ \\
\hline
\end{tabular}




$$
\begin{gathered}
N a O C H_{3}+R O H \stackrel{k_{N a O C H}}{\longrightarrow} C H_{3} O H+N a O R \\
(\phi O)_{3} P+N a O R \stackrel{k_{T P P}}{\longrightarrow}(\phi O)_{2} P O R+N a O \phi
\end{gathered}
$$




\section{DISCUSSION}

Laboratory runs using this reaction system were carried out prior to the beginning of this study. The experimental data are shown in Figures 4 through 12 . The reaction runs were made at temperatures of 110,130 , and $150^{\circ} \mathrm{C}$ with three reactant ratios of $1: 1,2.5: 1$, and $5: 1$ isodecanol to triphenyl phosphite at each temperature. Samples were taken in 15-minute intervals.

Two additional reaction runs were performed varying sodium methylate concentration and mixing rate. These two runs were performed using a 2.5:1 reactant ratio and a temperature of $130^{\circ} \mathrm{C}$. Samples were taken as quickly as possible at the onset of the reaction and slower as it progressed. Figures 13 and 14 show the experimental data. Several proposed mechanisms have been evaluated.

\section{Equilibrium catalyzed reaction}

The equilibrium system, as described by Equations 1 through 3, was considered. After developing the rate expressions based on simple power-law forms and equilibrium constant relations, the experimental data were reviewed. In all cases, the reactions progressed until a limiting reagent was encountered. This was clear evidence that the system was not described by this mechanism.

In addition, graphs of a kinetic model developed outside of this study based on these data were presented in an internal company presentation ${ }^{3}$. The model was presumably based on the same idea of equilibrium. Exact rate forms and constants were not given. Visual examination of the presentation graphs shows approximately 10 to $15 \%$ error when compared to the laboratory data. 


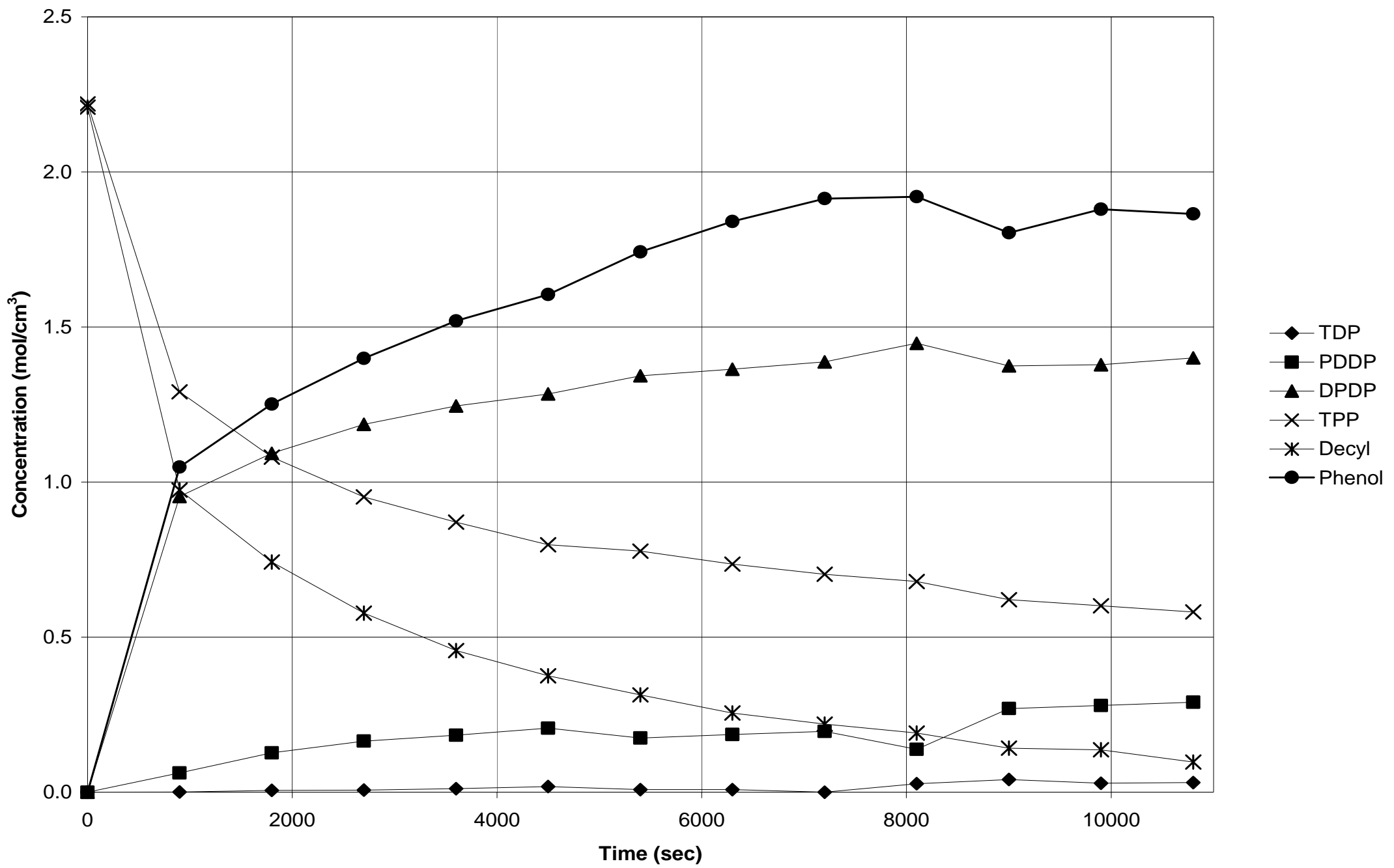

Figure 4: Results from 1:1 isodecanol to TPP ratio at $110^{\circ} \mathrm{C}$ 


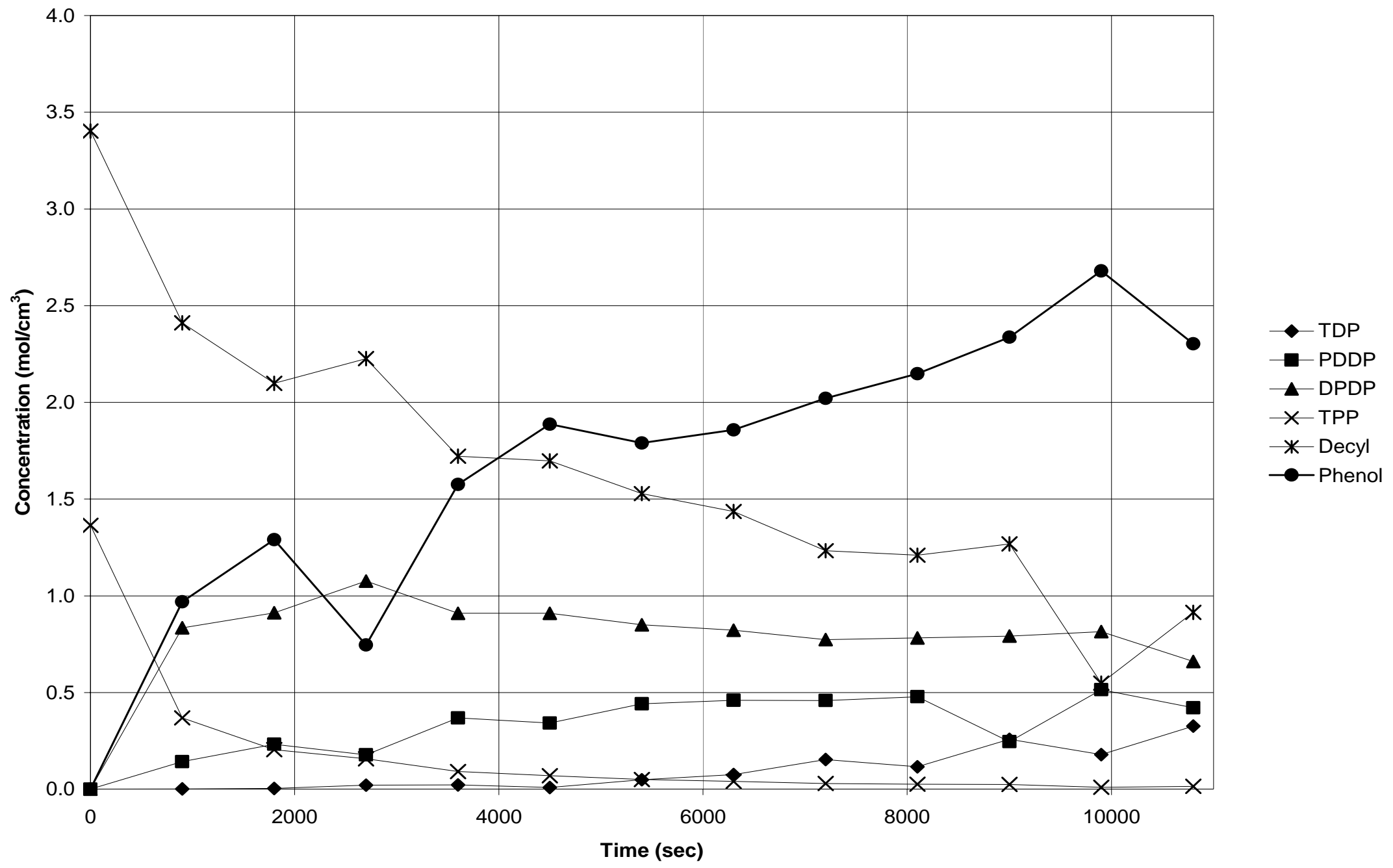

Figure 5: Results from $2.5: 1$ isodecanol to TPP ratio at $110^{\circ} \mathrm{C}$ 


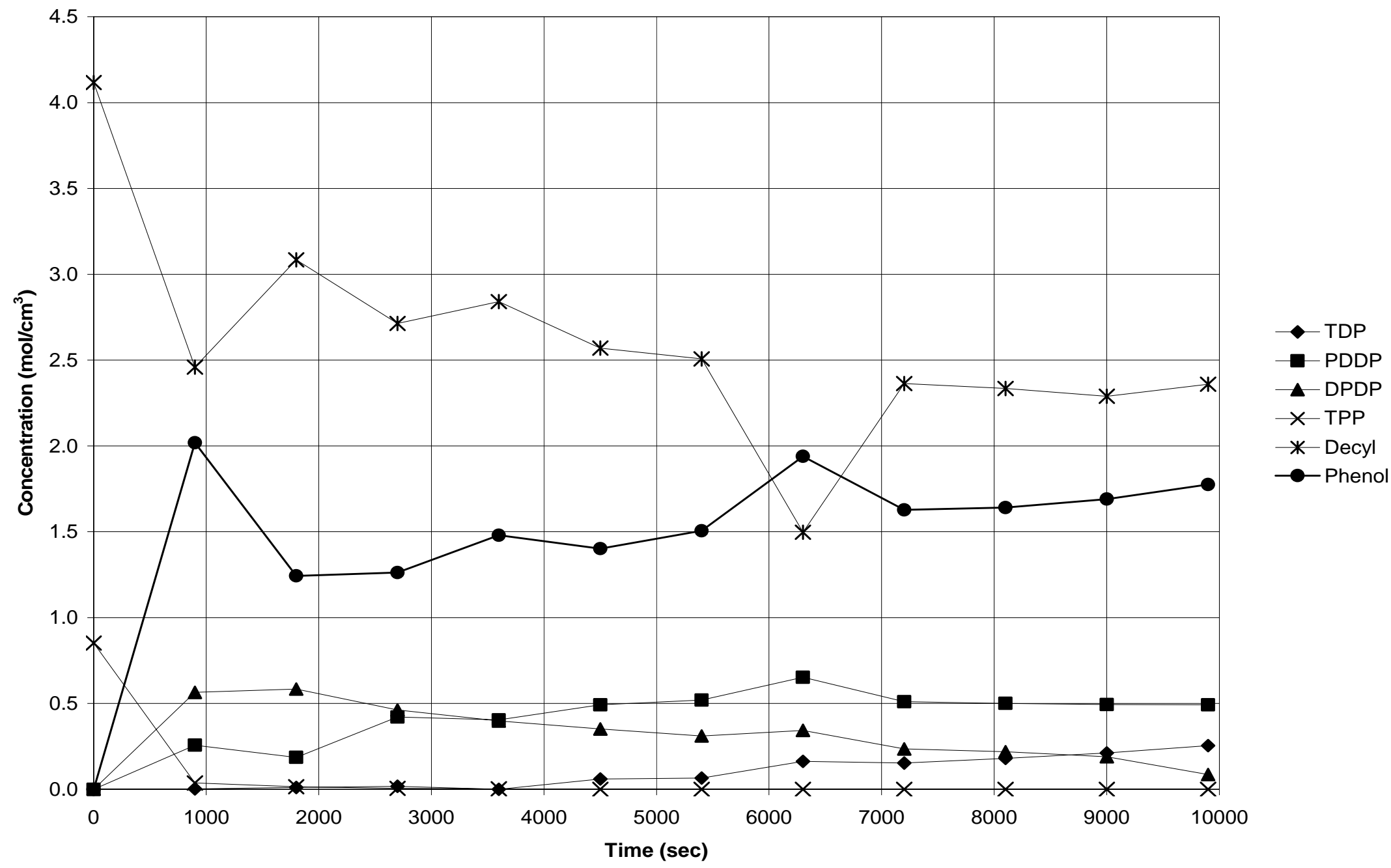

Figure 6: Results from 5:1 isodecanol to TPP ratio at $110^{\circ} \mathrm{C}$ 


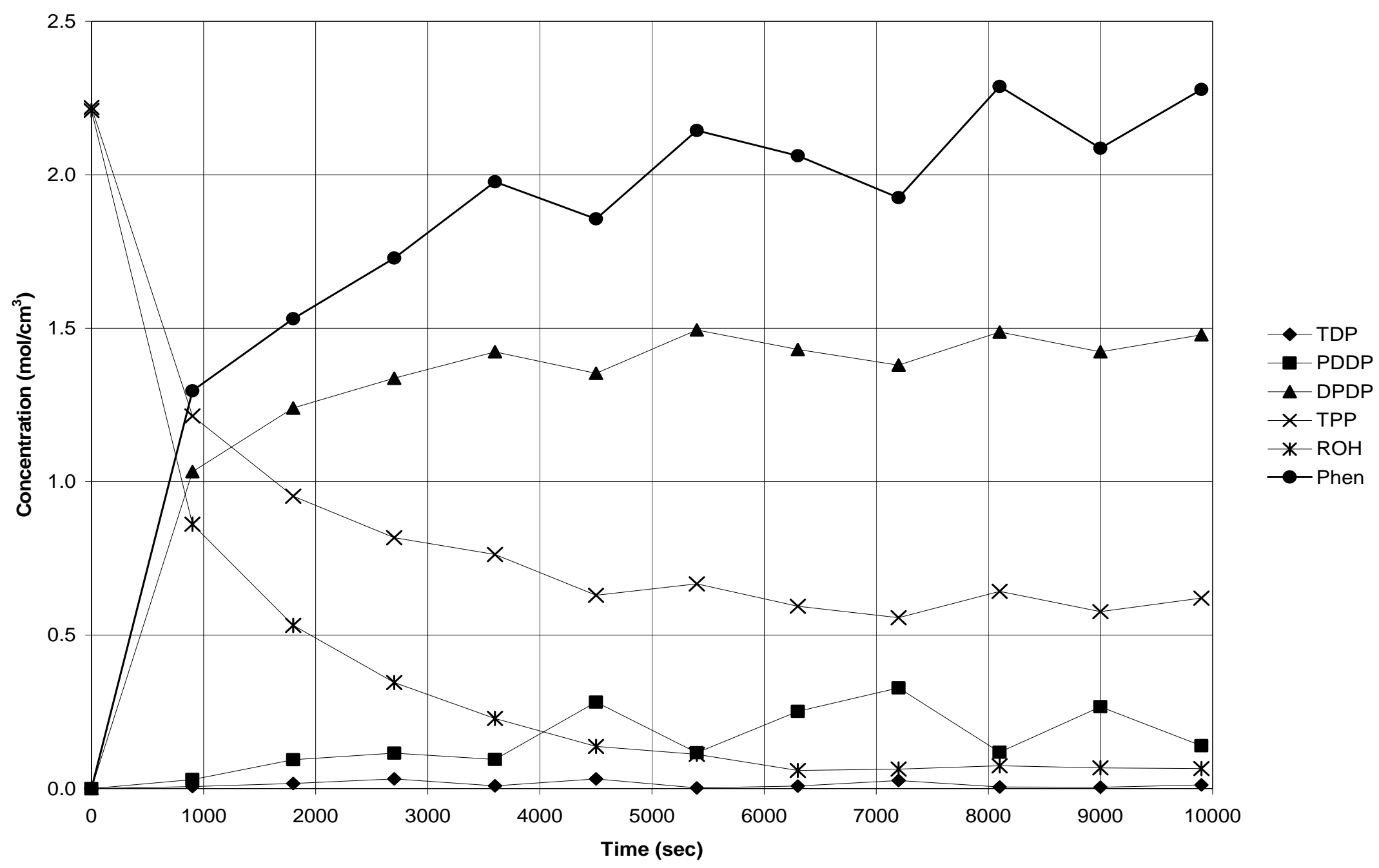

Figure 7: Results from 1:1 isodecanol to TPP ratio at $130^{\circ} \mathrm{C}$ 


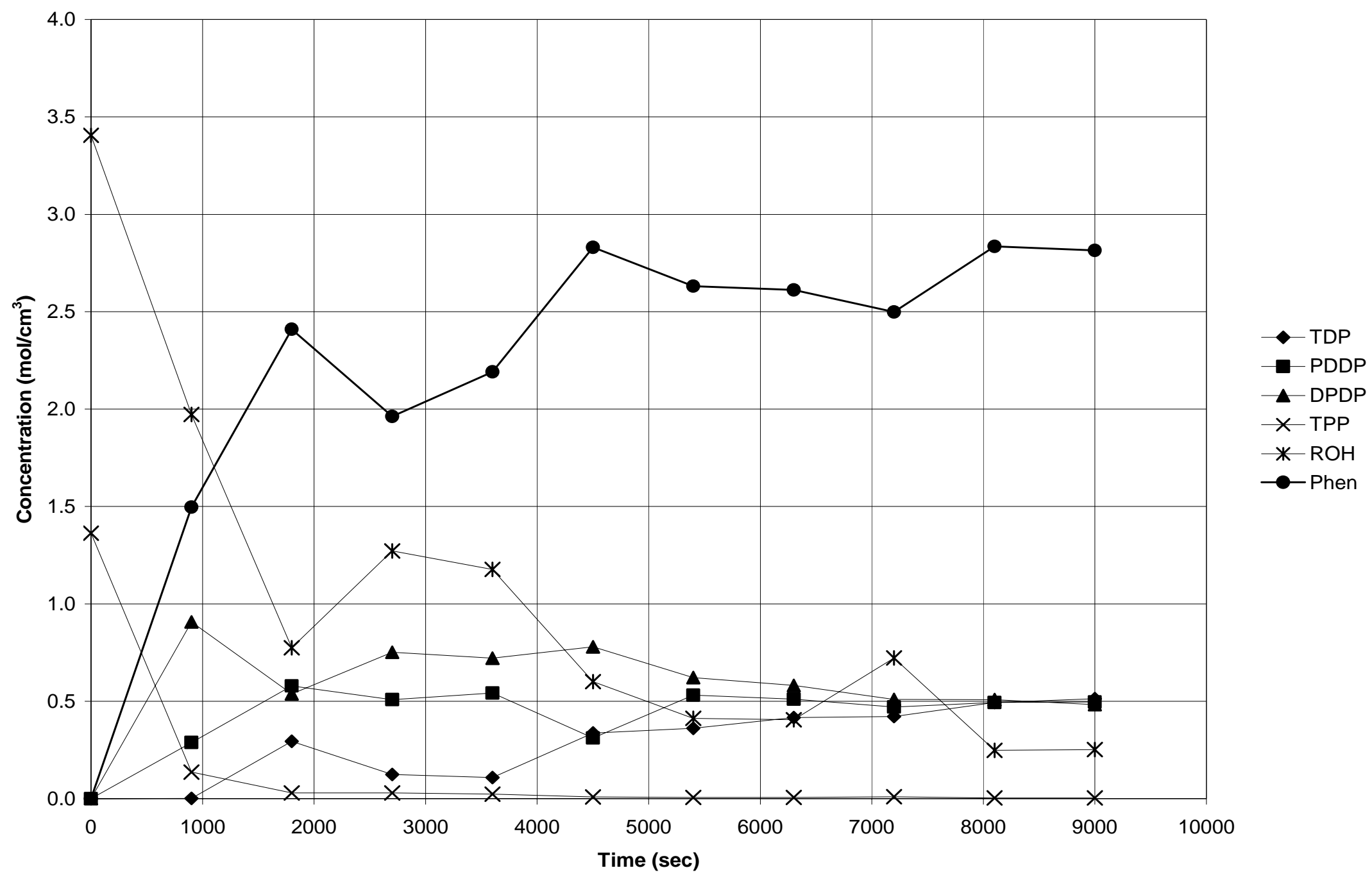

Figure 8: Results from 2.5:1 isodecanol to TPP ratio at $130^{\circ} \mathrm{C}$ 


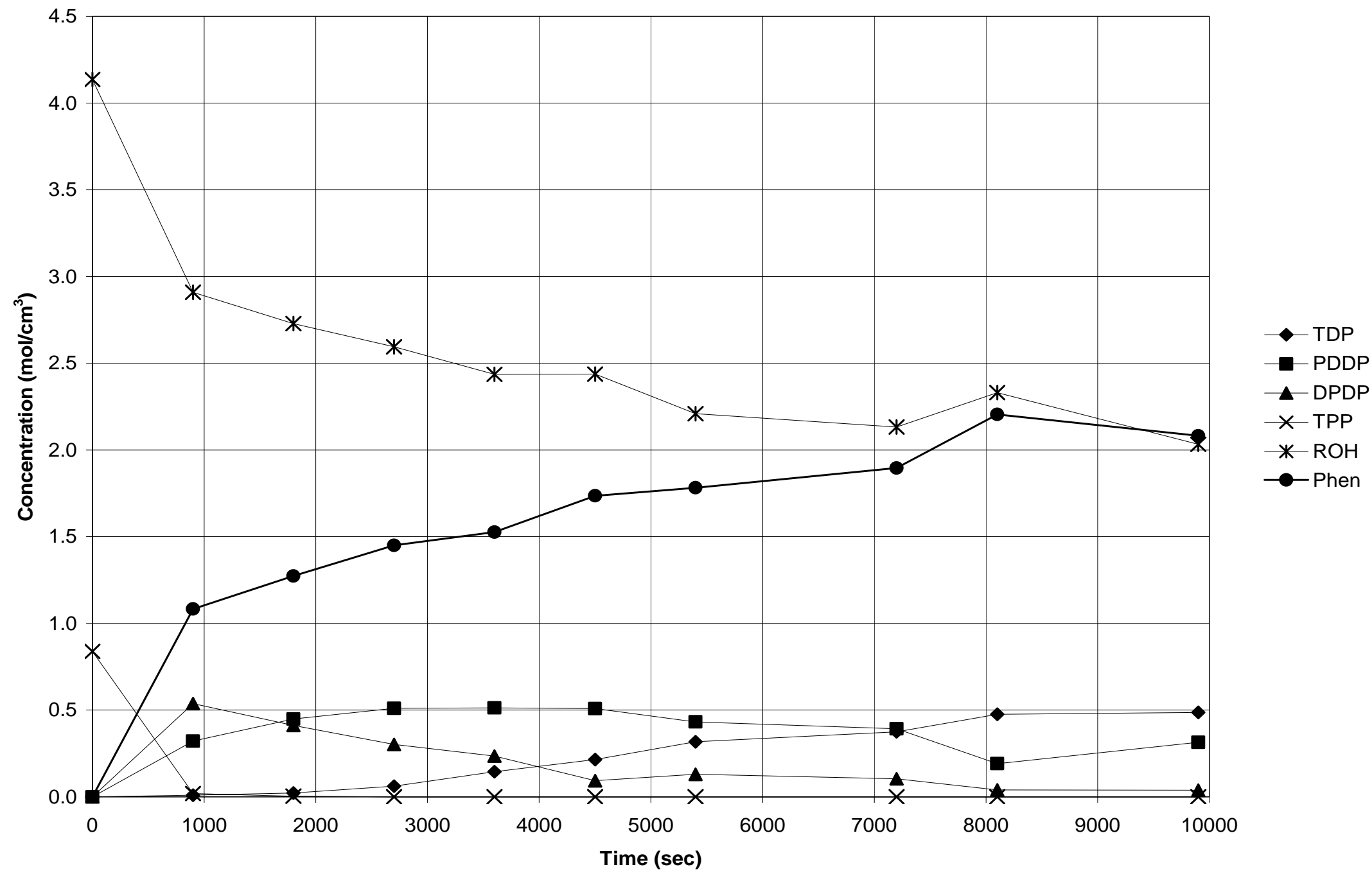

Figure 9: Results from 5:1 isodecanol to TPP ratio at $130^{\circ} \mathrm{C}$ 


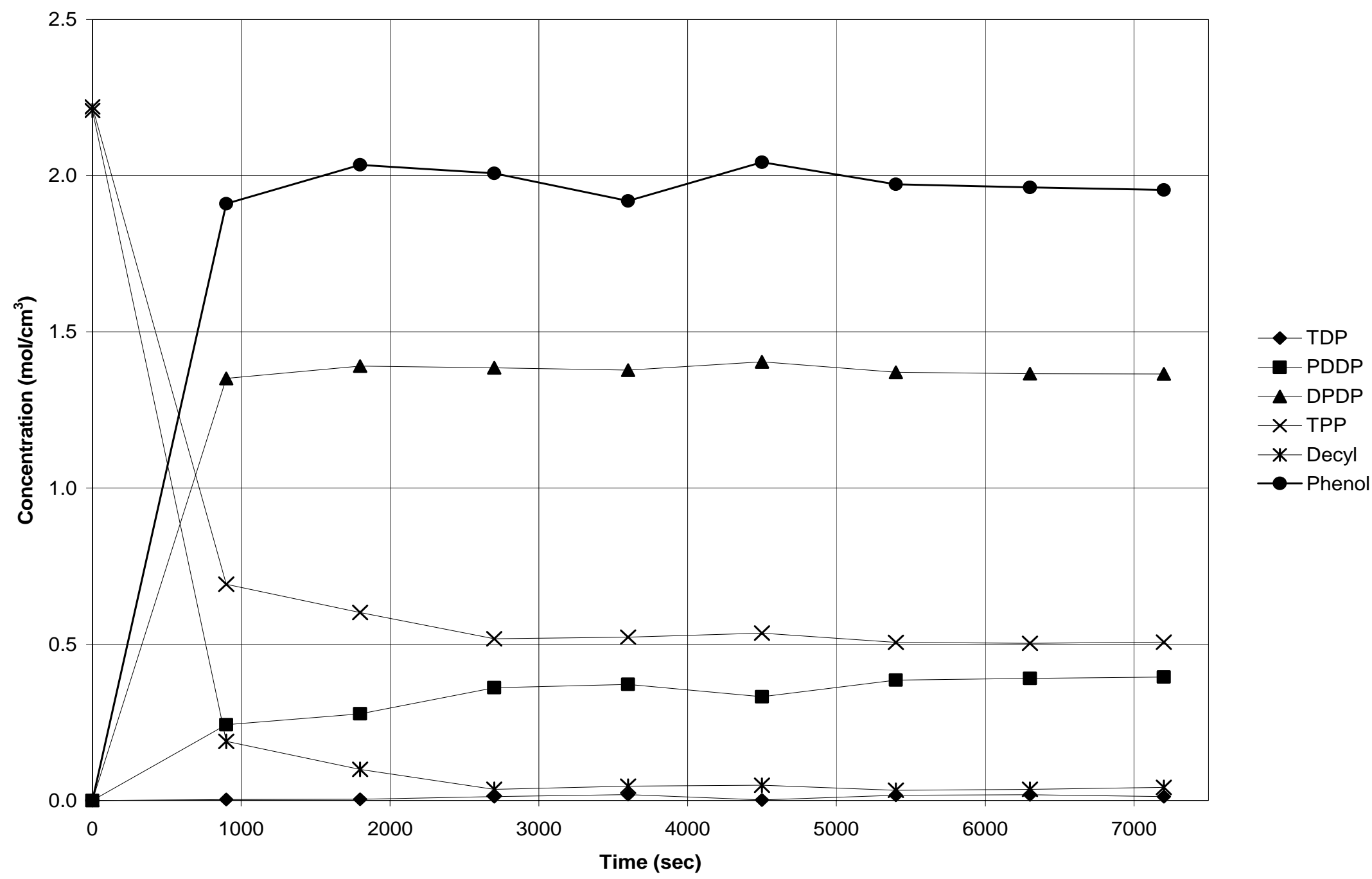

Figure 10: Results from 1:1 isodecanol to TPP ratio at $150^{\circ} \mathrm{C}$ 


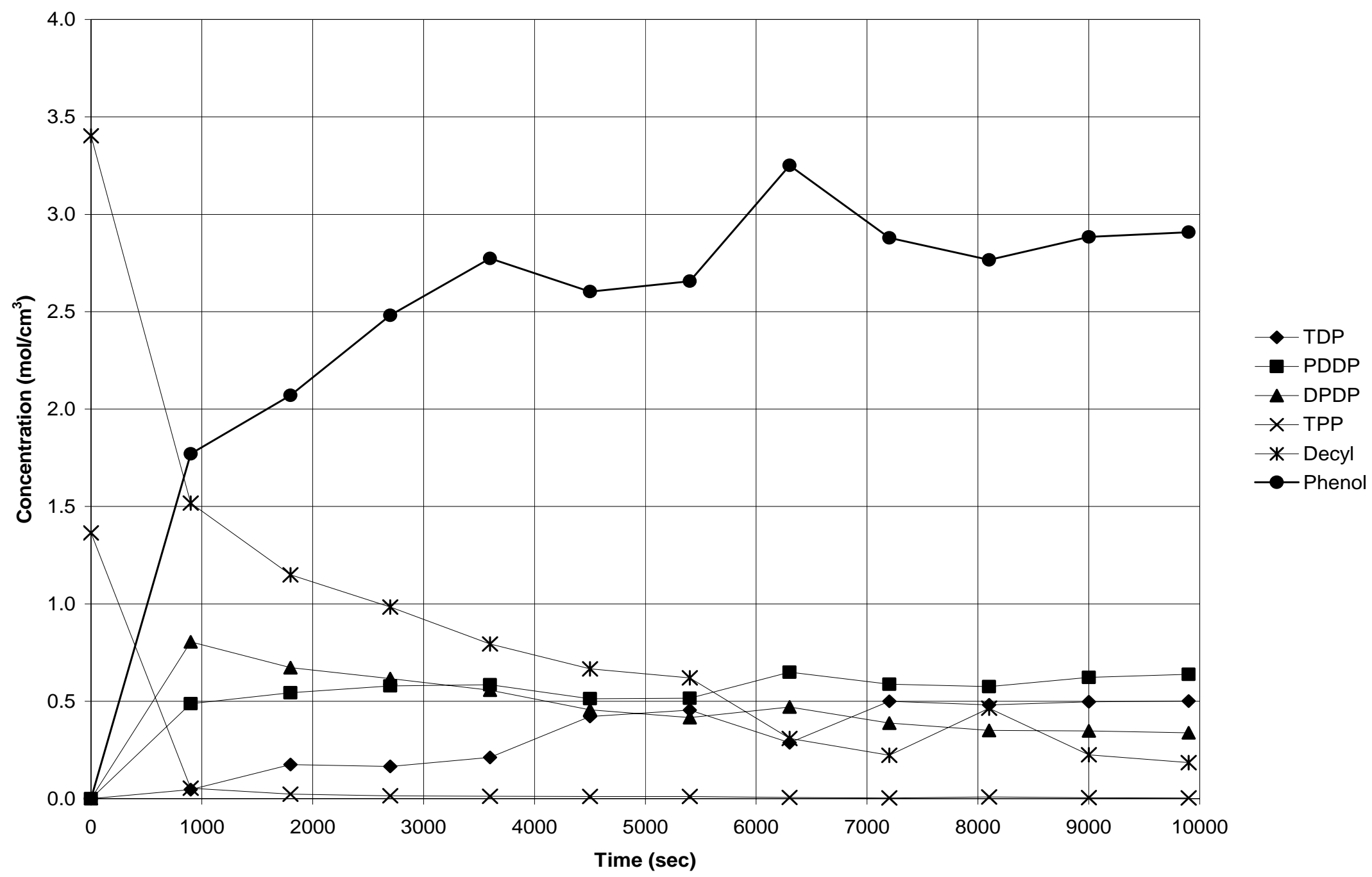

Figure 11: Results from 2.5:1 isodecanol to TPP ratio at $150^{\circ} \mathrm{C}$ 


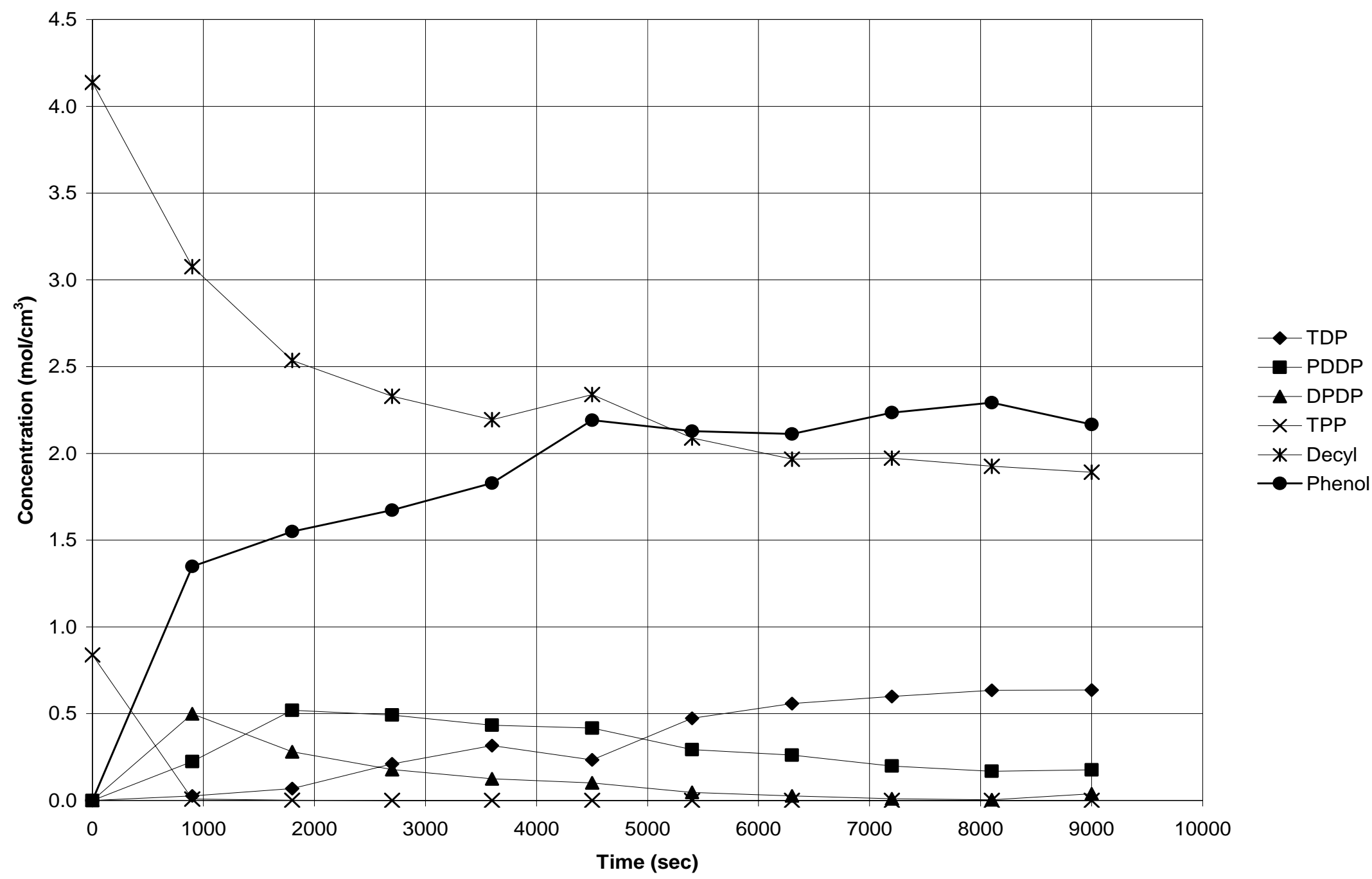

Figure 12: Results from 5:1 isodecanol to TPP ratio at $150^{\circ} \mathrm{C}$ 


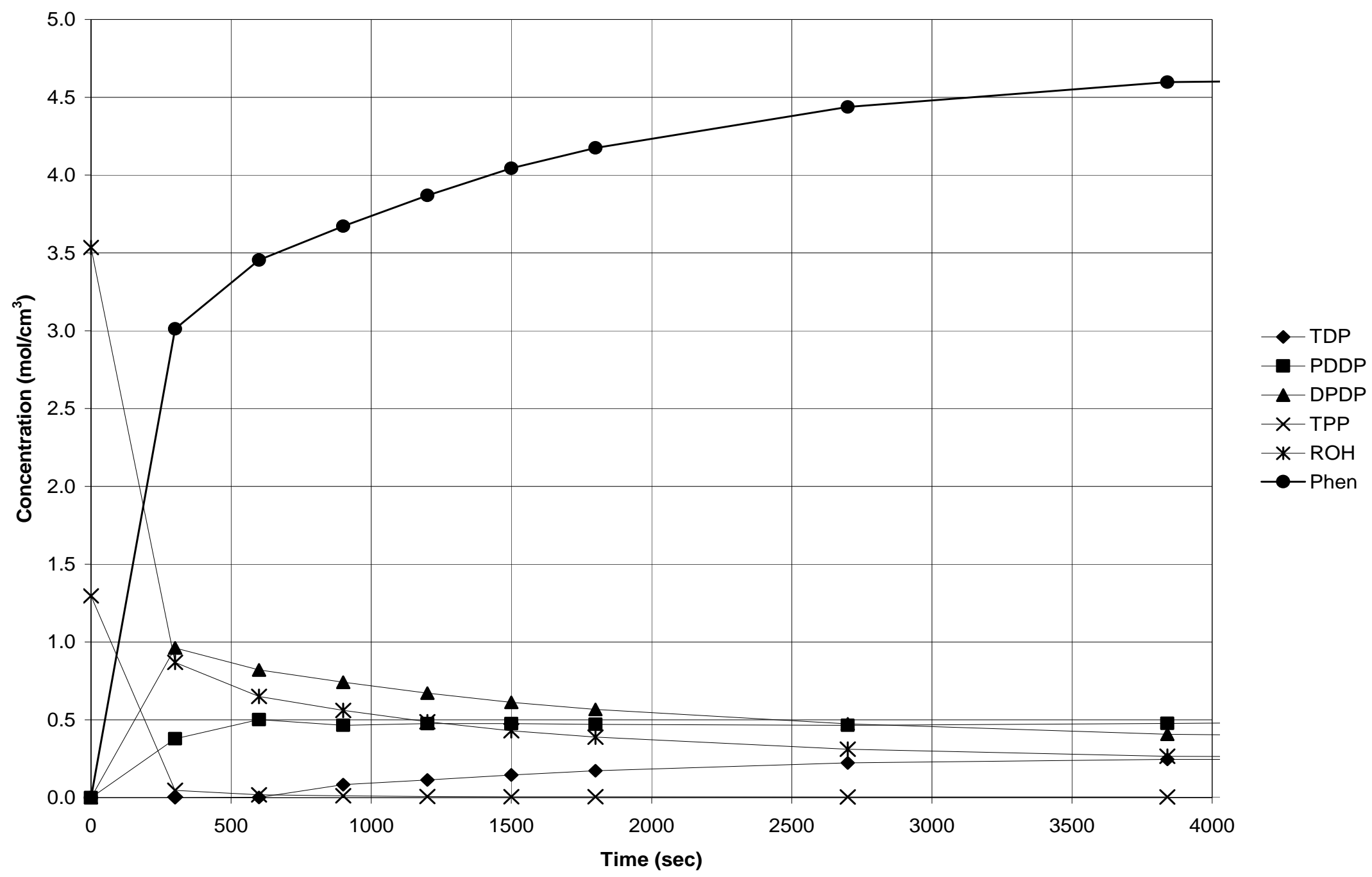

Figure 13: Results from 2.5:1 isodecanol to TPP ratio at $130^{\circ} \mathrm{C}$ with 0.04 grams of sodium methylate 


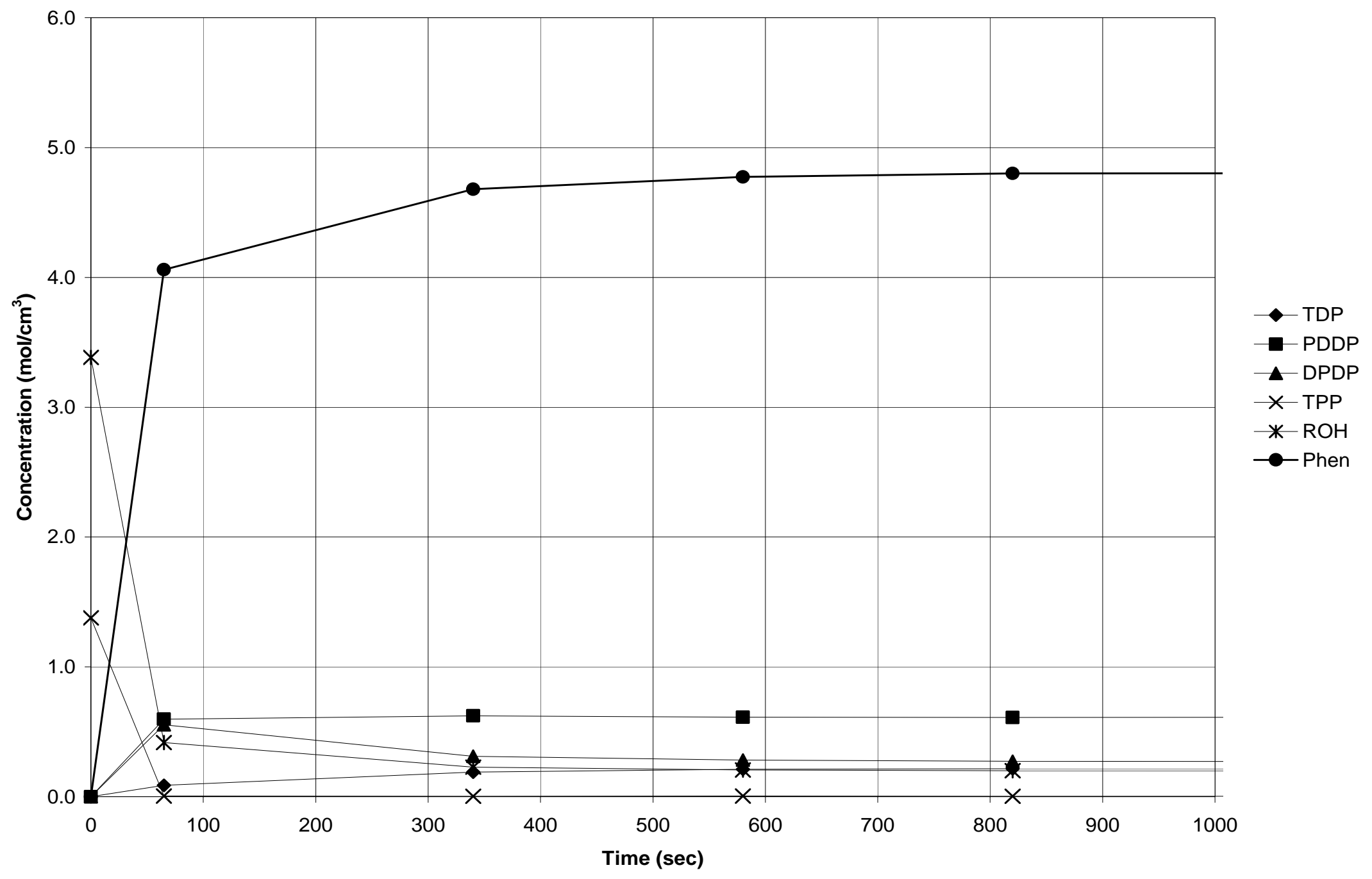

Figure 14: Results from 2.5:1 isodecanol to TPP ratio at $130^{\circ} \mathrm{C}$ with 0.4 grams of sodium methylate 


\section{Irreversible reaction with intermediate}

While reviewing the sodium methylate involvement, the mechanism described by Equations 8 through 12 was proposed. Viewing Equation 8 as an initiation reaction and assuming that Equation 12 proceeds much faster than those of Equations 9 through 11, it is reasonable to consider the sodium decylate concentration to be constant. The net reaction rate relationships under this assumption are shown in Equations 13 through 17.

$$
\begin{aligned}
& \mathrm{NaOCH}_{3}+\mathrm{ROH} \stackrel{k_{\mathrm{NaOCH}_{3}}}{\longrightarrow} \mathrm{CH}_{3} \mathrm{OH}+\mathrm{NaOR} \\
& (\phi O)_{3} \mathrm{P}+\mathrm{NaOR} \stackrel{k_{T P P}}{\longrightarrow}(\phi O)_{2} \mathrm{POR}+\mathrm{NaO} \phi \\
& (\phi O)_{2} \mathrm{POR}+\mathrm{NaOR} \stackrel{k_{D P D P}}{\longrightarrow} \phi \mathrm{OP}(\mathrm{OR})_{2}+\mathrm{NaO} \phi \\
& \phi \mathrm{OP}(\mathrm{OR})_{2}+\mathrm{NaOR} \stackrel{k_{P D D P}}{\longrightarrow} \mathrm{P}(\mathrm{OR})_{3}+\mathrm{NaO} \phi \\
& \mathrm{NaO} \phi+\mathrm{ROH} \stackrel{k_{\mathrm{NaO} \phi}}{\longrightarrow} \mathrm{NaOR}+\phi \mathrm{OH} \\
& -r_{T P P}=r_{D P D P_{(13)}} \\
& r_{D P D P}=r_{D P D P_{(13)}}-r_{P D D P_{(14)}} \\
& r_{P D D P}=r_{P D D P_{(14)}}-r_{T D P_{(15)}} \\
& r_{T D P}=r_{T D P_{(15)}} \\
& -r_{R O H}=r_{\phi O H}=r_{T P P}+r_{P D D P_{(14)}}+r_{T D P}
\end{aligned}
$$

Simple power-law rate expressions for this case were written and are given in Equations 23 through 27.

$$
\begin{gathered}
\frac{-d C_{T P P}}{d t}=k_{T P P} C_{T P P} C_{R O H} \\
\frac{d C_{D P D P}}{d t}=k_{T P P} C_{T P P} C_{R O H}-k_{D P D P} C_{D P D P} C_{R O H} \\
\frac{d C_{P D D P}}{d t}=k_{D P D P} C_{D P D P} C_{R O H}-k_{P D D P} C_{P D D P} C_{R O H} \\
\frac{d C_{T D P}}{d t}=k_{P D D P} C_{P D D P} C_{R O H} \\
\frac{d C}{d t}=\frac{-d C_{R O H}}{d t}=k_{T P P} C_{T P P} C_{R O H}+k_{D P D P} C_{D P D P} C_{R O H}+k_{P D D P} C_{P D D P} C_{R O H}
\end{gathered}
$$

The resulting coefficients from fitting the experimental data to this system are given in Table 3. The derivatives were estimated by numerical differentiation of the concentration and time data. Polymath was used to solve the system at the experimental conditions of 110,130 , 
and $150^{\circ} \mathrm{C}$ at 2.5:1 reactant ratio. The results are graphed in Figures 15 through 17 . The results reasonably follow observations at the lower two temperatures but then deviate somewhat at $150^{\circ} \mathrm{C}$.

Table 3: Regressed reaction coefficients for Equations 23 through 27

\begin{tabular}{|c|c|c|c|c|c|c|c|c|c||}
\hline \multirow{2}{*}{ Ratio } & \multicolumn{3}{|c|}{$T=110^{\circ} \mathrm{C}$} & \multicolumn{3}{c|}{$T=130^{\circ} \mathrm{C}$} & \multicolumn{3}{c||}{$T=150^{\circ} \mathrm{C}$} \\
\cline { 2 - 9 } & $k_{T P P}$ & $k_{D P D P}$ & $k_{P D D P}$ & $k_{T P P}$ & $k_{D P D P}$ & $k_{P D D P}$ & $k_{T P P}$ & $k_{D P D P}$ & $k_{P D D P}$ \\
\hline $\mathbf{1 : 1}$ & $3.01 \times 10^{-4}$ & $1.16 \times 10^{-5}$ & $3.96 \times 10^{-5}$ & $3.29 \times 10^{-4}$ & $3.94 \times 10^{-4}$ & $8.67 \times 10^{-5}$ & $5.14 \times 10^{-4}$ & $2.78 \times 10^{-3}$ & $2.72 \times 10^{-5}$ \\
\hline $\mathbf{2 . 5 : 1}$ & $3.50 \times 10^{-4}$ & $5.67 \times 10^{-5}$ & $8.27 \times 10^{-5}$ & $4.35 \times 10^{-4}$ & $1.55 \times 10^{-4}$ & $1.20 \times 10^{-4}$ & $4.70 \times 10^{-4}$ & $6.00 \times 10^{-4}$ & $1.25 \times 10^{-4}$ \\
\hline $\mathbf{5 : 1}$ & $3.87 \times 10^{-4}$ & $9.13 \times 10^{-5}$ & $2.72 \times 10^{-5}$ & $3.93 \times 10^{-4}$ & $2.70 \times 10^{-4}$ & $5.91 \times 10^{-5}$ & $3.99 \times 10^{-4}$ & $4.66 \times 10^{-4}$ & $9.07 \times 10^{-5}$ \\
\hline \hline
\end{tabular}

The rate constants appear to follow the familiar Arrhenius relationship shown in Equations 28 through 30. Table 2 gives the regressed values for $A$, the frequency factor, and $E$,

$$
\begin{gathered}
k_{T P P}(T)=A_{T P P} e^{\frac{-E_{T P P}}{R T}} \\
k_{D P D P}(T)=A_{D P D P} e^{\frac{-E_{D P D P}}{R T}} \\
k_{P D D P}(T)=A_{P D D P} e^{\frac{-E_{P D D P}}{R T}}
\end{gathered}
$$

the activation energy for each constant at each reactant ratio. A data point for the rate constant of PDDP in a 1:1 reactant ratio at $150^{\circ} \mathrm{C}$ was omitted on the basis of gross error because the directional change was contrary to the direction of the previous two temperatures. In other words, the data point suggested the reaction slowed as the temperature increases when all other data suggested the opposite. The frequency factor for $k_{D P D P}$ seems to be unreasonable compared to the others. This is either due to error of regressing with limited data or because power-law kinetics may not govern over the analyzed range. 


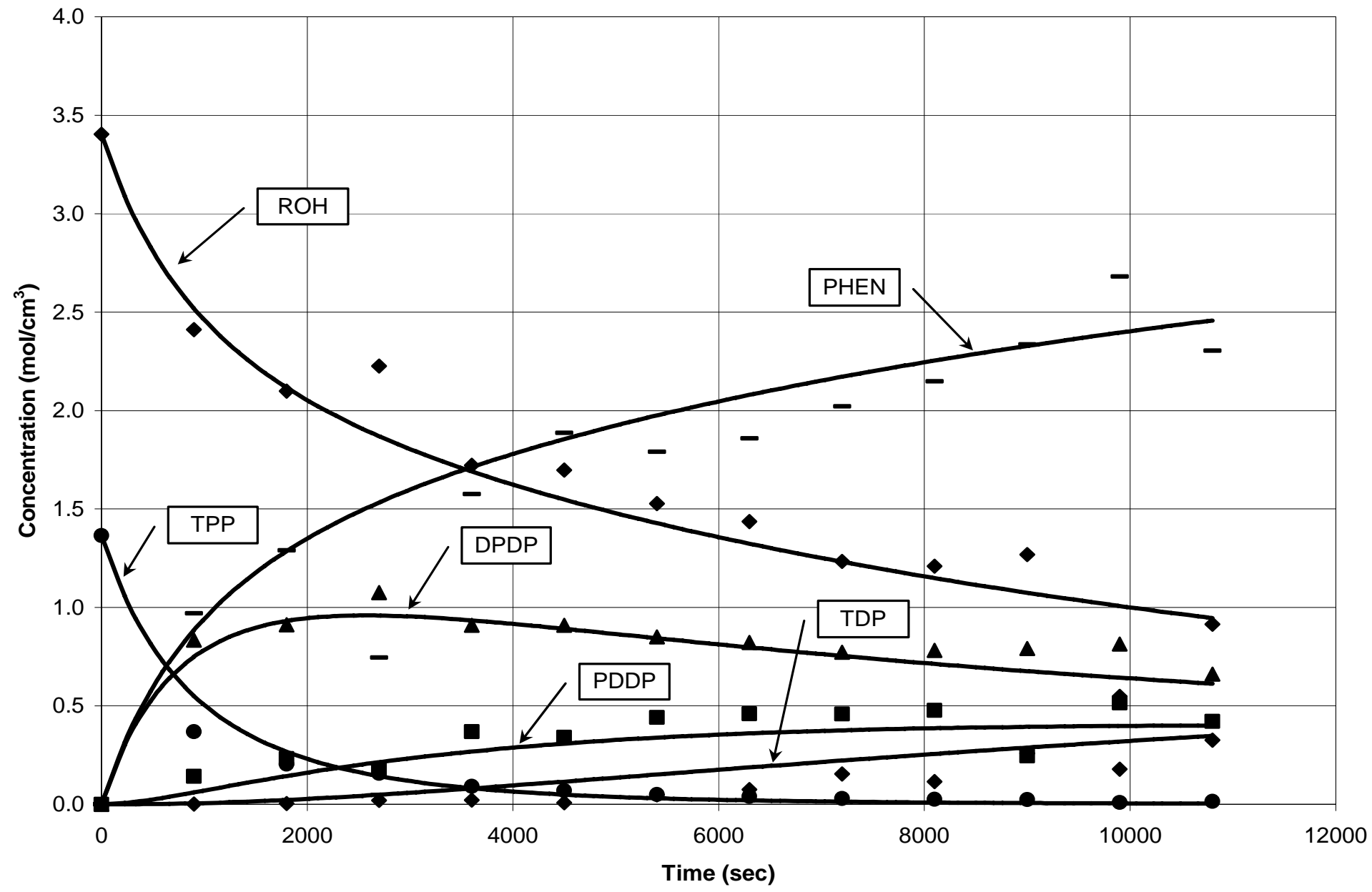

- TPP

$\triangle D P D P$

- PDDP

$\bullet$ TDP

$\bullet \mathrm{ROH}$

-PHEN

Figure 15: Power law kinetic model comparison for $2.5: 1$ reactant ratio at $110^{\circ} \mathrm{C}$ 


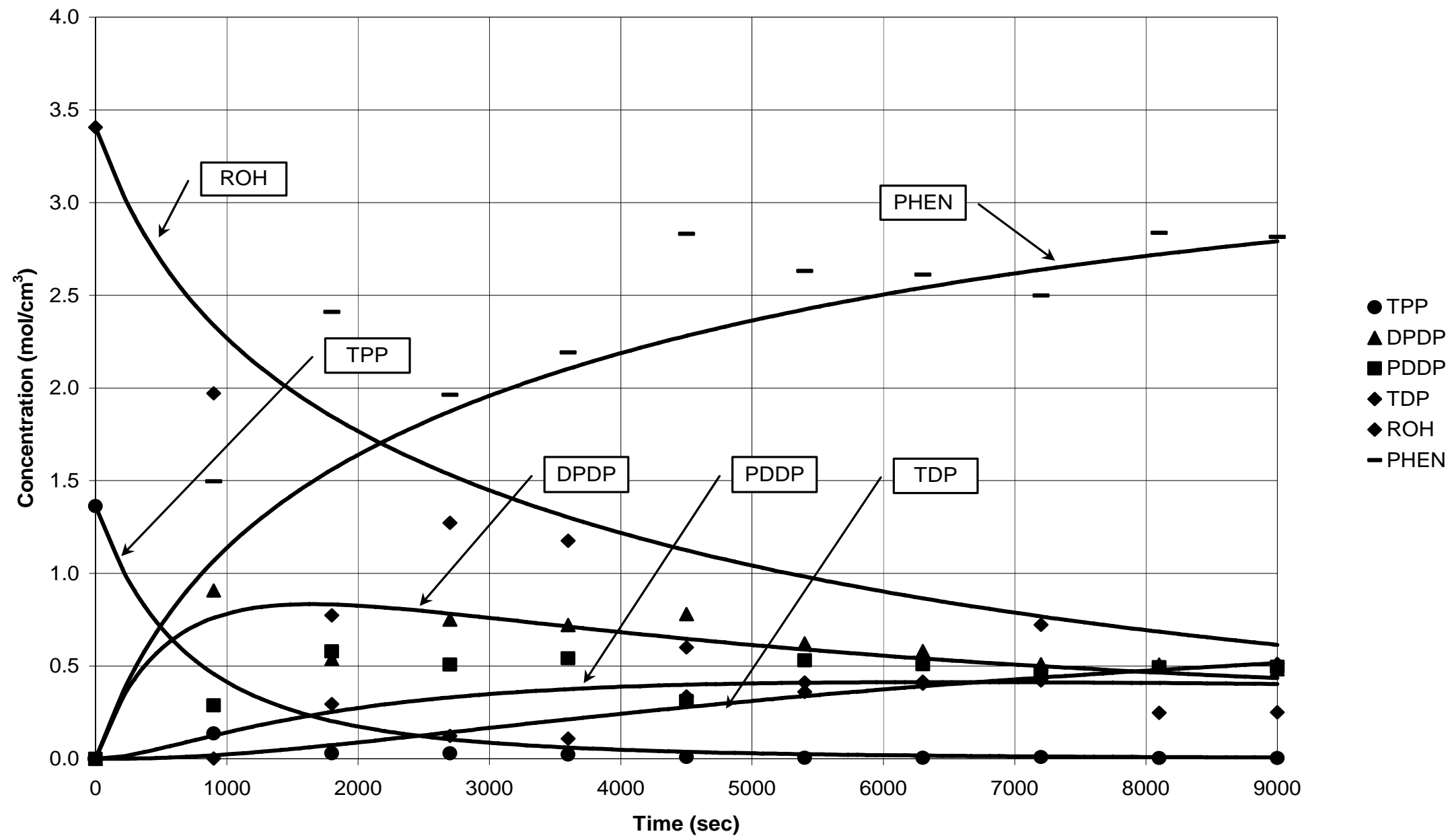

Figure 16: Power law kinetic model comparison for $2.5: 1$ reactant ratio at $130^{\circ} \mathrm{C}$ 


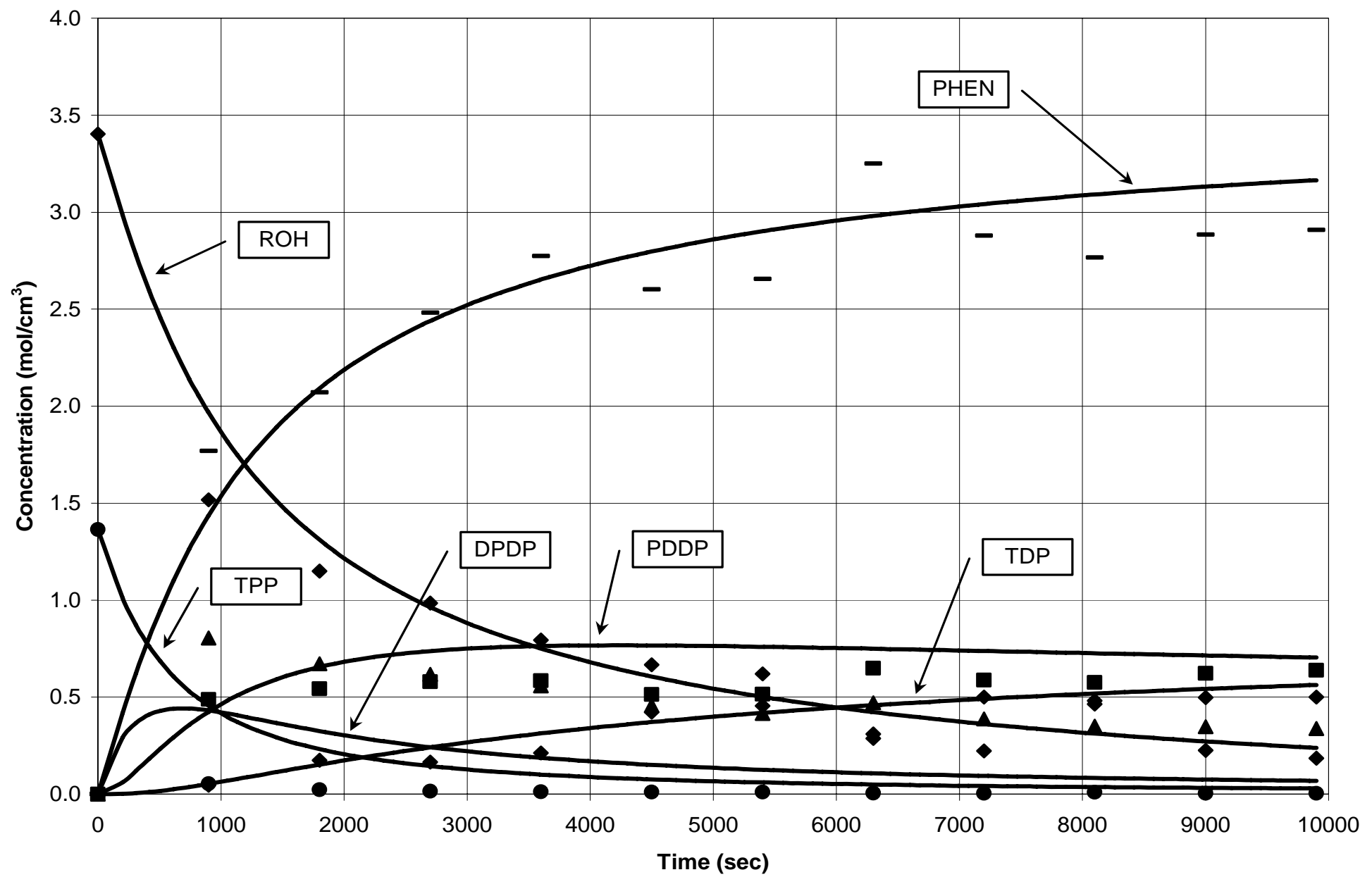

- TPP

$\triangle$ DPDP

$\square \mathrm{PDDP}$

$\checkmark$ TDP

- $\mathrm{ROH}$

- PHEN

Figure 17: Power law kinetic model comparison for $2.5: 1$ reactant ratio at $150^{\circ} \mathrm{C}$ 
Substituting Equations 28 through 30 into Equations 23 through 27 gives the following general rate expressions for the decyl phosphite system as seen in the Results section. Figure 18 shows this general model versus experimental data for the case of a 2.5 ratio and $110^{\circ} \mathrm{C}$ for comparison against Figure 15. It is suggested that the Arrhenius equation factors, $A$ and $E$, be extrapolated for reactant ratios not given in Table 2. As with any data set, care should be taken if values are extrapolated outside of the studied range and is not recommended.

$$
\begin{gathered}
\frac{-d C_{T P P}}{d t}=A_{T P P} e^{\frac{-E_{T P P}}{R T}} C_{T P P} C_{R O H} \\
\frac{d C_{D P D P}}{d t}=A_{T P P} e^{\frac{-E_{T P P}}{R T}} C_{T P P} C_{R O H}-A_{D P D P} e^{\frac{-E_{D P D P}}{R T}} C_{D P D P} C_{R O H} \\
\frac{d C_{P D D P}}{d t}=A_{D P D P} e^{\frac{-E_{D P D P}}{R T}} C_{D P D P} C_{R O H}-A_{P D D P} e^{\frac{-E_{P D D P}}{R T}} C_{P D D P} C_{R O H}
\end{gathered}
$$

It is suspected that the frequency factor may be related to the reactant ratio but further analysis of these constants did not provide meaningful insight. The frequency factor and activation energy was fit to a second order polynomial of the reactant ratio for each species. The coefficients are shown in Table 4. The resulting polynomials do not provide stable results across the studied region of reactant ratios. For example, the frequency factor polynomial for $k_{P D D P}$ exhibits a minimum between the reactant ratios of 2.5 and 5 of about $-72 \mathrm{sec}^{-1}$ and the activation energy polynomial for $k_{T P P}$ exhibits a negative minimum. Negative values are physically unreasonable for either of these factors. The notion of a set of general equations involving the reactant ratio as an independent variable to describe the reaction system was abandoned. 


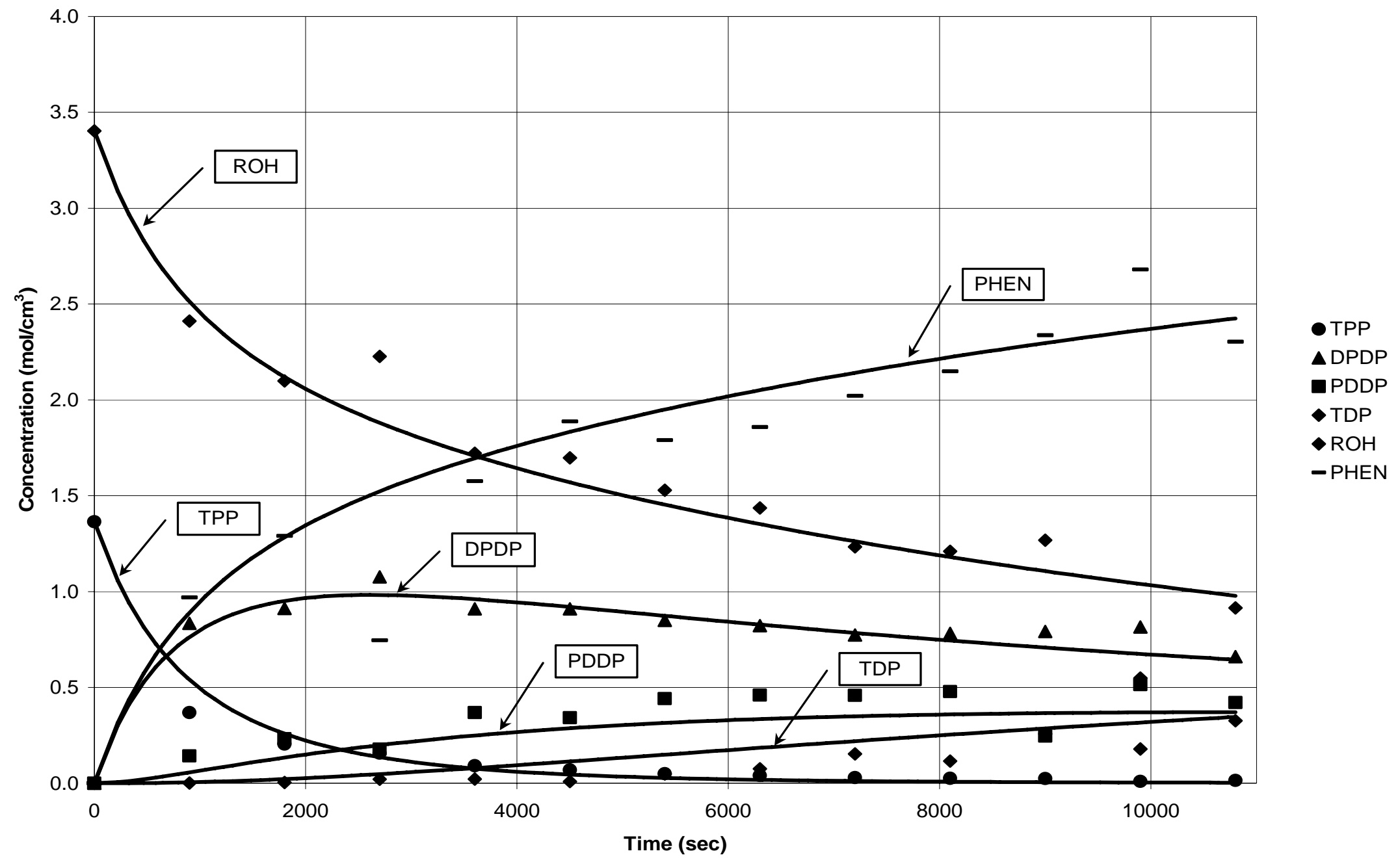

Figure 18: General power law kinetic model comparison for $2.5: 1$ reactant ratio at $110^{\circ} \mathrm{C}$ 
Table 4: Coefficients for polynomial fit of Arrhenius equation parameters to reactant ratio

\begin{tabular}{||l|r|r|c|r|r|r||}
\hline \hline & \multicolumn{2}{|c|}{$k_{T P P}$} & \multicolumn{2}{c|}{$k_{D P D P}$} & \multicolumn{2}{|c||}{$k_{P D D P}$} \\
\cline { 2 - 7 } & $A\left(\mathrm{sec}^{-1}\right)$ & $E(\mathrm{~J} / \mathrm{mol} \mathrm{K})$ & $A\left(\mathrm{sec}^{-1}\right)$ & $E(\mathrm{~J} / \mathrm{mol} \mathrm{K})$ & $A\left(\mathrm{sec}^{-1}\right)$ & $E(\mathrm{~J} / \mathrm{mol} \mathrm{K})$ \\
\hline $\mathrm{a}_{2}$ & 0.011 & 400 & $4.27 \times 10^{19}$ & 15223 & 49 & 8667 \\
\hline $\mathrm{a}_{1}$ & -0.082 & -6608 & $-3.20 \times 10^{20}$ & -123815 & -366 & -54400 \\
\hline $\mathrm{a}_{0}$ & 0.148 & 24008 & $5.33 \times 10^{20}$ & 293592 & 607 & 96033 \\
\hline \multicolumn{6}{|l}{ Polynomial $=\mathrm{a}_{2} \mathrm{z}^{2}+\mathrm{a}_{1} \mathrm{z}+\mathrm{a}_{0}$, where $\mathrm{z}$ is the reactant molar ratio } \\
\hline
\end{tabular}

\section{Limited but Fixed Reactant}

While it is reasonable to consider the sodium decylate concentration constant, the decreasing accuracy as temperature increases of the power-law form model may suggest that the formation of sodium decylate is not fast enough to provide enough reactant for the three competing phosphite steps. Levenspiel ${ }^{4}$ discusses how some reactions may follow MichaelisMenten kinetics if the rate-controlling step is associated with a limited but fixed amount of reactant. If the conversion of sodium phenate back to sodium decylate is not fast enough relative to the phosphite reactions, then this would be the case.

Applying the simplest concentration relationships for Michaelis-Menten kinetics to rate relationships in Equations 13 through 17 results in the rate forms given in Equations 31 through 35.

$$
\begin{array}{r}
\frac{-d C_{T P P}}{d t}=\frac{k_{1} C_{T P P}}{1+k_{1}^{\prime} C_{T P P}} \\
\frac{d C_{D P D P}}{d t}=\frac{k_{1} C_{T P P}}{1+k_{1}^{\prime} C_{T P P}}-\frac{k_{2} C_{D P D P}}{1+k_{2}^{\prime} C_{D P D P}} \\
\frac{d C_{P D D P}}{d t}=\frac{k_{2} C_{D P D P}}{1+k_{2}^{\prime} C_{D P D P}}-\frac{k_{3} C_{P D D P}}{1+k_{3}^{\prime} C_{P D D P}} \\
\frac{d C_{T D P}}{d t}=\frac{k_{3} C_{P D D P}}{1+k_{3}^{\prime} C_{P D D P}} \\
\frac{k_{4} C_{R O H}}{d t}=\frac{d C_{\phi O H}}{d t}=\frac{k_{1} C_{T P P}}{1+k_{1}^{\prime} C_{T P P}}+\frac{k_{2} C_{D P D P}}{1+k_{2}^{\prime} C_{D P D P}}+\frac{k_{3} C_{P D D P}}{1+k_{3}^{\prime} C_{P D D P}}=\frac{k_{4}^{\prime} C_{R O H}}{1+k_{2}}
\end{array}
$$

Separating variables and integrating Equation 31 results in a form that can be rearranged to give a linear equation to easily evaluate experimental data. This linear form is given in Equation 36 . The graphical results for experimental data are shown in Figures 19 through 21. The same linear form was used to find $k_{4}$ and $k_{4}^{\prime}$ in Equation 35 associated with the rate of disappearance of 
isodecanol. The rate constants are summarized in Table 5 along with the $\mathrm{R}^{2}$ value from the regression. This model does not appear to be any better than the power-law model presented above.

$$
\frac{\ln \left(\frac{C_{T P P_{0}}}{C_{T P P}}\right)}{\left(C_{T P P_{0}}-C_{T P P}\right)}=k_{1}\left(\frac{t}{\left(C_{T P P_{0}}-C_{T P P}\right.}\right)-k_{1}^{\prime}
$$

Table 5: Rate constants for Equations 31 and 35

\begin{tabular}{|l|c|c|c|c|c|c|c|c|c|}
\hline \multirow{2}{*}{ Constant } & \multicolumn{3}{|c}{$T=110^{\circ} \mathrm{C}$} & \multicolumn{3}{c|}{$T=130^{\circ} \mathrm{C}$} & \multicolumn{3}{c|}{$T=150^{\circ} \mathrm{C}$} \\
\cline { 2 - 9 } & $\mathbf{1 : 1}$ & $\mathbf{2 . 5 : 1}$ & $\mathbf{5 : 1}$ & $\mathbf{1 : 1}$ & $\mathbf{2 . 5 : 1}$ & $\mathbf{5 : 1}$ & $\mathbf{1 : 1}$ & $\mathbf{2 . 5 : 1}$ & $\mathbf{5 : 1}$ \\
\hline$k_{1}$ & $4.0 \times 10^{-5}$ & $3.0 \times 10^{-4}$ & $9.0 \times 10^{-4}$ & $3.0 \times 10^{-5}$ & $4.0 \times 10^{-4}$ & $1.9 \times 10^{-3}$ & $2.0 \times 10^{-5}$ & $2.0 \times 10^{-4}$ & $2.3 \times 10^{-3}$ \\
\hline$k_{1}^{\prime}$ & 0.5763 & 1.1801 & 2.8213 & 0.6373 & 2.1462 & 2.5719 & 0.7838 & 2.7134 & 3.1085 \\
\hline Fit $R^{2}$ & 0.9638 & 0.9598 & 0.9920 & 0.6884 & 0.8289 & $N / A$ & 0.6503 & 0.8190 & $N / A$ \\
\hline$k_{4}$ & $1.8 \times 10^{-4}$ & $5.5 \times 10^{-5}$ & $2.6 \times 10^{-6}$ & $2.5 \times 10^{-4}$ & $1.5 \times 10^{-4}$ & $1.1 \times 10^{-5}$ & $1.9 \times 10^{-4}$ & $1.8 \times 10^{-4}$ & $1.8 \times 10^{-5}$ \\
\hline$k_{4}^{\prime}$ & 0.5263 & 0.2851 & 0.3054 & 0.6769 & 0.3509 & 0.2845 & 1.3744 & 0.3353 & 0.2816 \\
\hline Fit $R^{2}$ & 0.9937 & 0.5234 & 0.0212 & 0.8429 & 0.5829 & 0.7895 & 0.5607 & 0.8202 & 0.8207 \\
\hline
\end{tabular}

An attempt was made to determine the remaining rate constants by non-linear regression using the experimental data for a reactant ratio of $2.5: 1$ at a temperature of $130^{\circ} \mathrm{C}$. This was unsuccessful. The regression fits were very poor and did describe the data being fit.

It was noted that as the ratio increased, i.e. higher excess of isodecanol, the apparent curvature of the data in Figures 19 through 21 decreases. This may imply that the correct rate form should include a second species, perhaps the sodium decylate intermediate. Equation 37 is the result of extending the Michaelis-Menten kinetic form to include two reactants ${ }^{5}$. This kinetic form can not be tested because the measurement of this species was not possible with the available analytical methods. 


$$
\frac{-d C_{T P P}}{d t}=\frac{k_{1} C_{T P P} C_{R O-N a}}{k_{2}+k_{3} C_{T P P}+k_{4} C_{R O-N a}+C_{T P P} C_{R O-N a}}
$$

Expanding this concept for the rate expressions and still assuming that the isodecanol concentration is representative of the sodium decylate concentration results in Equations 38 through 42. The regressed coefficients for the experimental data observed at $110^{\circ} \mathrm{C}$ and a reactant ratio of $2.5: 1$ are shown in Table 6 . Figure 22 shows a graph of the model and the experimental data.

$$
\begin{gathered}
\frac{-d C_{T P P}}{d t}=\frac{K_{1} C_{T P P} C_{R O H}}{k_{1}+k_{T P P} C_{T P P}+k_{R O H_{1}} C_{R O H}+C_{T P P} C_{R O H}} \\
\frac{d C_{D P D P}}{d t}=\frac{K_{1} C_{T P P} C_{R O H}}{k_{1}+k_{T P P} C_{T P P}+k_{R O H_{1}} C_{R O H}+C_{T P P} C_{R O H}}
\end{gathered}
$$




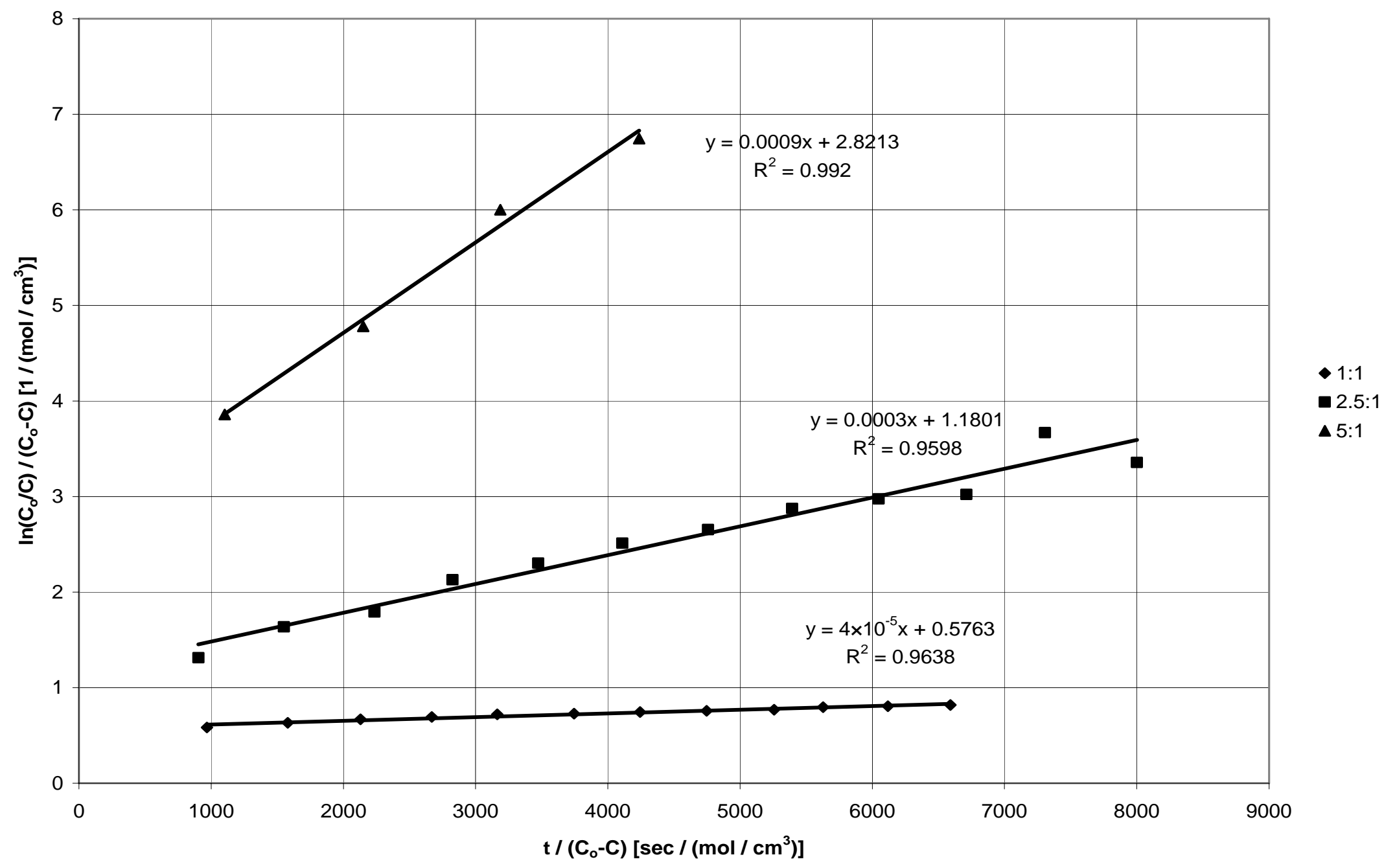

Figure 19: Michaelis-Menten coefficient determination at $110^{\circ} \mathrm{C}$ 


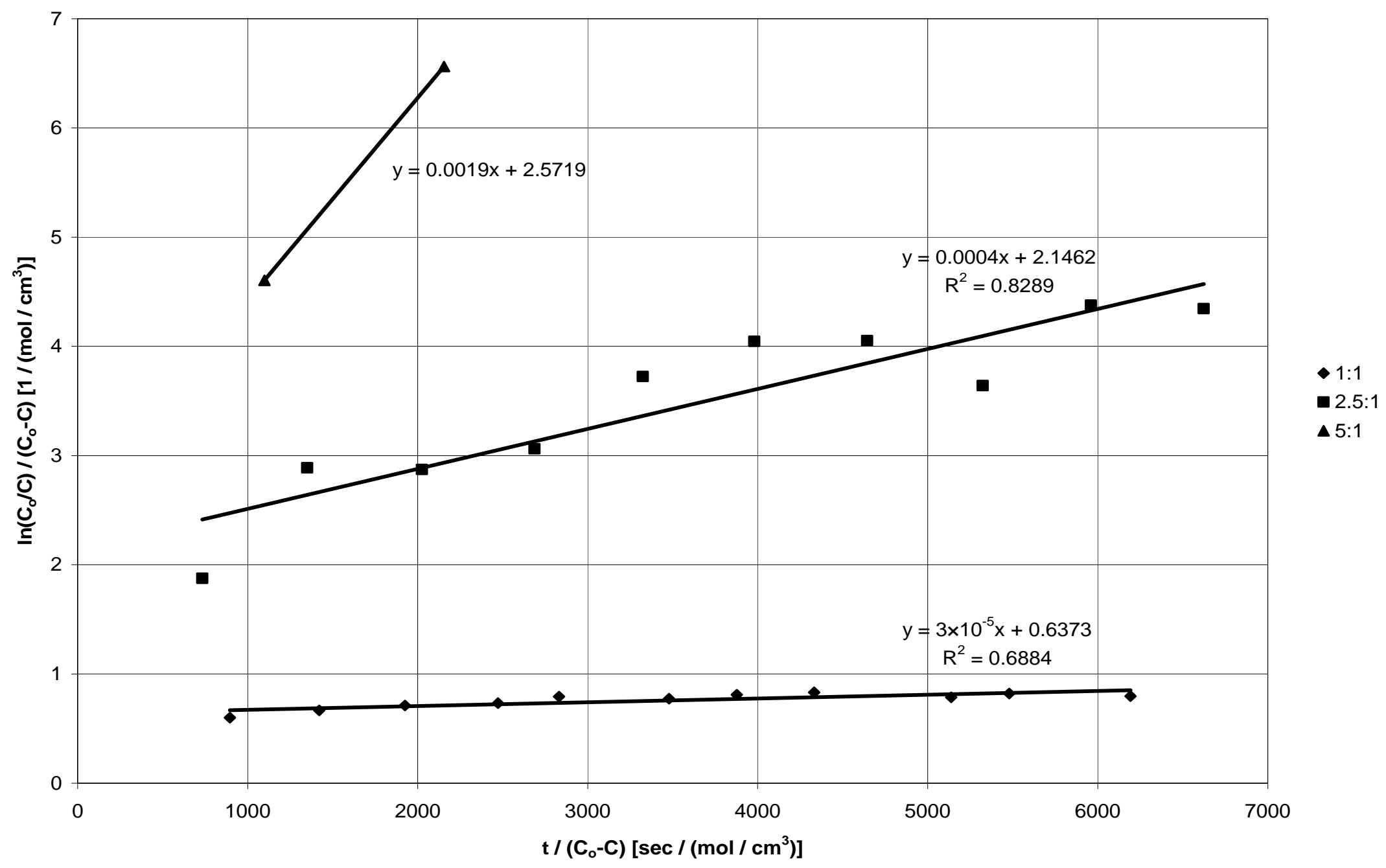

Figure 20: Michaelis-Menten coefficient determination at $130^{\circ} \mathrm{C}$ 
33

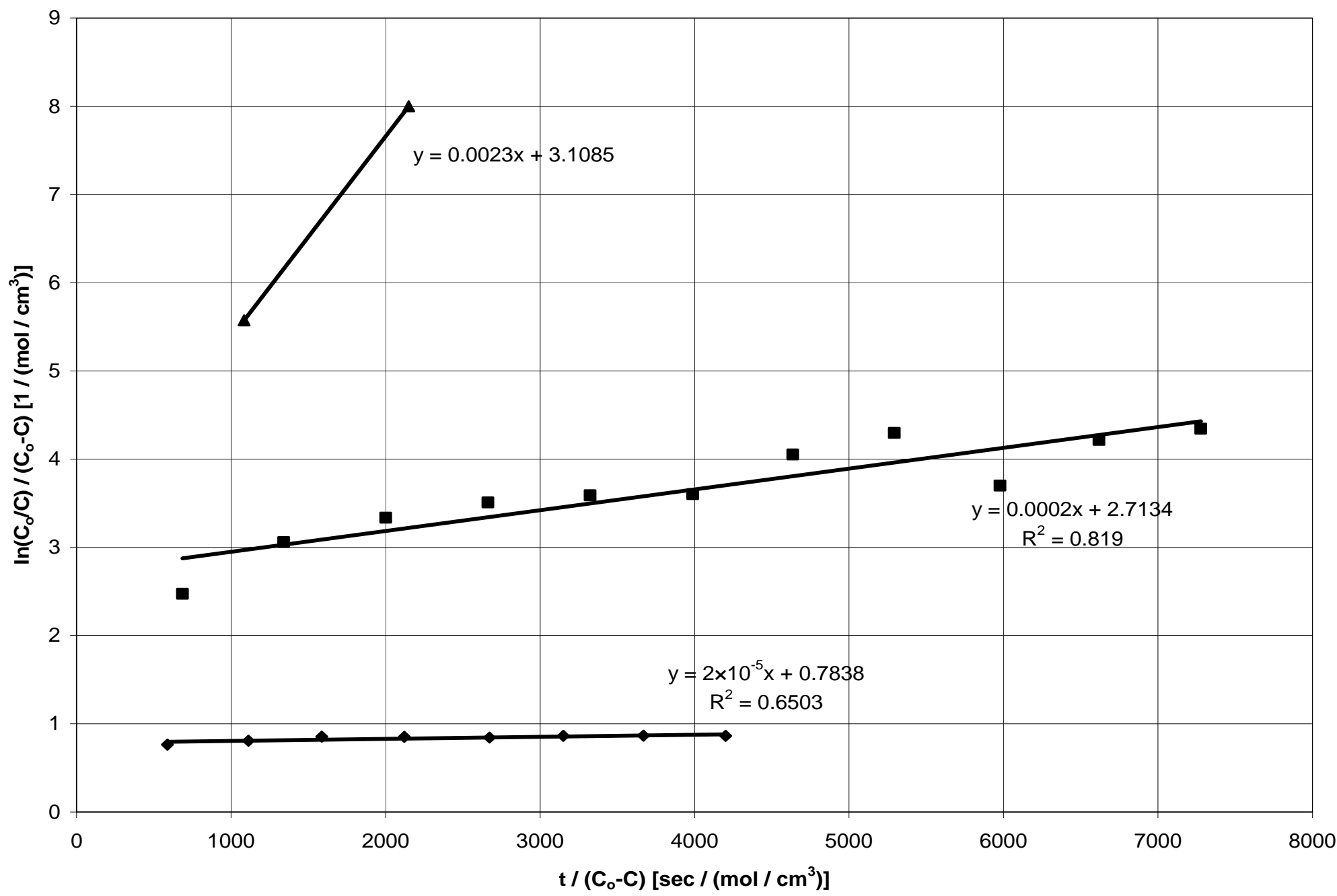

- $1: 1$

2.5:1

\ 5:1

Figure 21: Michaelis-Menten coefficient determination at $150^{\circ} \mathrm{C}$ 
Table 6: Regression results for Equations 38 through 42 for reactant ratio of $2.5: 1$ at $110^{\circ} \mathrm{C}$

\begin{tabular}{|c|c|c|c|}
\hline $\boldsymbol{K}_{\mathbf{1}}$ & $\boldsymbol{k}_{\mathbf{1}}$ & $\boldsymbol{k}_{\mathrm{TPP}}$ & $\boldsymbol{k}_{\mathrm{ROH} 1}$ \\
\hline $6.13 \times 10^{-3}$ & 1.00 & 3.62 & 1.72 \\
\hline $\boldsymbol{K}_{\mathbf{2}}$ & $\boldsymbol{k}_{\mathbf{2}}$ & $\boldsymbol{k}_{\mathrm{DPDP}}$ & $\boldsymbol{k}_{\mathrm{ROH} 2}$ \\
\hline $4.00 \times 10^{-3}$ & 1.00 & 9.63 & 7.06 \\
\hline $\boldsymbol{K}_{\mathbf{3}}$ & $\boldsymbol{k}_{\mathbf{3}}$ & $\boldsymbol{k}_{\mathrm{PDDP}}$ & $\boldsymbol{k}_{\mathrm{ROH} 3}$ \\
\hline $2.16 \times 10^{-4}$ & 1.00 & 1.38 & 0.684 \\
\hline
\end{tabular}

The model does not predict the experimental data adequately. This does not, however, mean the model is not valid. The regression of the coefficients was very sensitive to initial guesses. It is believed that a set of coefficients exist that adequately describe the system at each reactant ratio and temperature. Solution to these situations has not been found. Numerous solutions were found that gave good statistical fit to the data but would cause the rate equations to change sign depending on concentration values. These coefficient solutions are not physically meaningful. A method of solving for the best set of coefficients within a physically meaningful space is needed before this kinetic form can be fully assessed. 


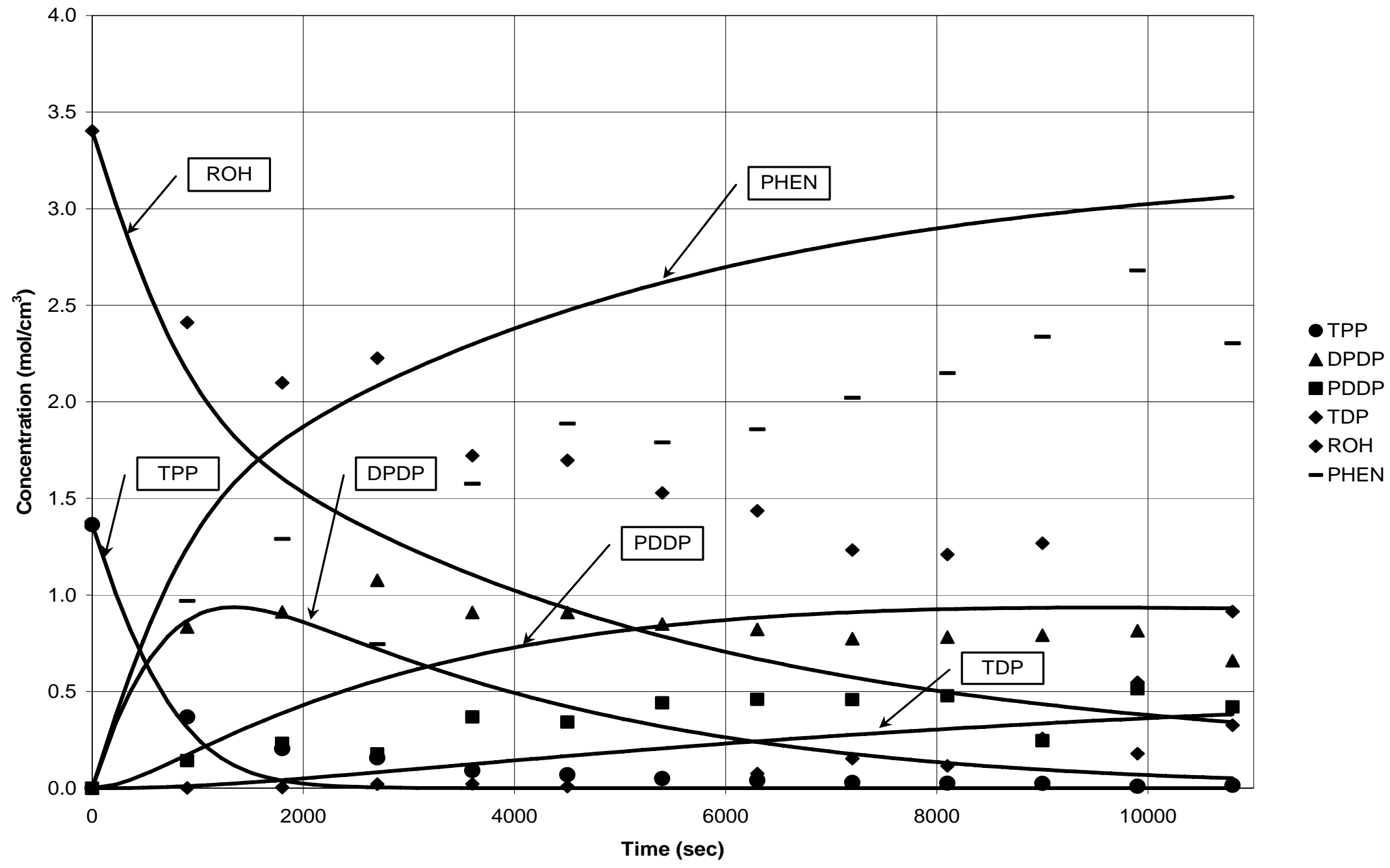

Figure 22: Two-reactant Michaelis-Menten kinetic model comparison for $2.5: 1$ reactant ratio at $110^{\circ} \mathrm{C}$ 


\section{Alternative reaction system}

If sodium decylate was isolated and used as the reactant in place of isodecanol, then the kinetics should follow traditional power-law forms and limitations imposed by the limited reactant would be eliminated. Sodium decylate can be created by reacting sodium methylate and isodecanol using methanol as a common solvent. The expected reactions are shown in Equations 43 through 45.

$$
\begin{array}{r}
(\phi O)_{3} P+N a O R \stackrel{k_{T P P}}{\longrightarrow}(\phi O)_{2} P O R+N a O \phi \\
(\phi O)_{2} P O R+N a O R \stackrel{k_{D P D P}}{\longrightarrow} \phi O P(O R)_{2}+N a O \phi \\
\phi O P(O R)_{2}+N a O R \stackrel{k_{P D D P}}{\longrightarrow} P(O R)_{3}+N a O \phi
\end{array}
$$

A laboratory experiment was performed to make sodium decylate using the same apparatus described in the Experimental Methods section with the addition of a vent condenser. A sufficient amount of methanol was added to the flask. After starting the circulation of chilled glycol through the vent condenser, sodium methylate and isodecanol were added to the methanol in stoichiometric proportion. The solution was then heated gently and the methanol was collected

through the vent condenser. The sodium decylate crystals remained and were collected from the flask.

No experiments were run beyond the creation of the sodium decylate crystals. Issues around the pursuit of this alternative reaction system include the commercial handling and delivery of the sodium decylate, the recovery of the sodium from the sodium phenate, and the purification of the decyl phosphites. Initially, any production of the decyl phosphites through the proposed system would be at an economic disadvantage compared to current manufacturing practices. This is out of the scope of this study. 


\section{CONCLUSION}

Isodecyl phosphites are used to enhance the stability of polymers during processing and subsequent use. The decyl phosphites have been commercially produced for over fifty years using batch reactors without a detailed understanding of the reaction mechanism and associated kinetics. The commercial production of this family of stabilizers could be enhanced through better understanding of this complex reaction system. By gaining insight, improvements to today's batch processes are possible. This understanding is also the foundation from which to design a continuous reactor system in the future.

The decyl phosphite stabilizer reaction system is a complex series that, when run under the right conditions, can be described adequately by the power-law rate equations depicted in Equations 18 through 22 and values found in Table 2. Conditions that seem to allow this behavior are sodium methylate concentrations of less than $0.015 \mathrm{wt} \%$ and reaction temperatures at or below $150^{\circ} \mathrm{C}$. Outside of this range the assumptions of constant and / or available sodium decylate are no longer valid. Under those conditions, the reaction rate does not follow power-law kinetics.

Recommendations for future work include solving for coefficient sets to Equations 38 through 42 and completing the model assessment, improving the sampling and analytical methods for the species of the system, perform the laboratory reactions at additional temperatures to define the frequency factors and activation energies, and study the alternative reaction system to determine its viability. 


\section{REFERENCES}

${ }^{1}$ Ryan, Terry, Personal Communication, September 2005.

${ }^{2}$ Marlin, Gary, Personal Communication, September-October 2005

3 Jack F. Welch Technology Center, PowerPoint presentation, 2002

${ }^{4}$ Levenspiel, Octave, Chemical Reaction Engineering, Hoboken, New Jersey: John Wiley \& Sons, Inc., 1999.

${ }^{5}$ Internet resource, Enzyme Kinetics, http://www.chem.qmul.ac.uk/iubmb/kinetics/ek4t6.html. 